\title{
Técnica y sistemática de la preparación y construcción de carillas de porcelana
}

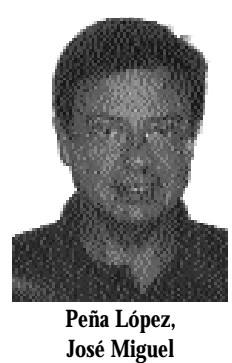

\author{
Procedure and clinical aspects of dental preparation \\ and technical fabrication of ceramic laminate veneers
}

Peña-López, José Miguel*

Fernández-Vázquez, J osé Pablo**

Álvarez-Fernández, Mariáángeles*

González-Lafita, Pedro***

*Doctor en Medicina, Estomatólogo, Profesor Asociado de Prótesis Estomatológica.

**Doctor en Medicina, Estomatólogo, Profesor Titular Interino.

***Doctor en Medicina, Estomatólogo, Colaborador de Honor de Prótesis Estomatológica.

Facultad de Medicina y Odontología de la Universidad de Oviedo
Resumen: Las carillas de porcelana son un tratamiento restaurador que ha probado su bondad después de muchos años de uso clínico, especialmente en el sector anterior por sus implicaciones estéticas, con porcentajes de éxito próximos al 95\%a los 15 años. En el presente artículo se hace una exposición del tratamiento con carillas de porcelana, incluyendo las indicaciones y contraindicaciones para su empleo, sus ventajas e inconvenientes, el diagnóstico, la comunicación con el paciente, las técnicas de preparación dentaria, el cementado de las mismas y el mantenimiento posterior.

Palabras clave: Carillas de porcelana, Carillas cerámicas, Cementos de composite, Estética dental, Adhesión

Abstract: Laminate ceramic veneers are very usefull for both dentists and patients as they are a good dental treatment, specially on the aesthetical part of the smile, with. Authors reveal a $95 \%$ of good results after 15 years in the mouth. In this article, the authors present a review on ceramic laminate veneers, including indications and contraindications of use, advantages and disadvantages, diagnosis procedures, patient communication, dental preparation techniques, luting techniques and maintenance.

Key words: Ceramic laminate veneers, Luting resin cements, Dental aesthetics, Adhesion

BIBUD [1138-123X (2003)8:6; noviembre-diciembre 593-724]

Peña López J M, Fernández Vázquez J P, Álvarez Fernández MA, González Lafita P. Técnica y sistemática clínica de la preparación y construcción de carillas de porcelana. RCOE 2003;8(6):647-668. 


\section{Introducción}

La continua mejora de los materiales y técnicas protésicas ha permitido que el aspecto estético de algunas restauraciones se fundamente en la cerámica sin metal, tanto para los dientes anteriores como, con menos indicaciones, en posteriores. Varios autores ${ }^{1-3}$ han revisado la cuestión y concluyeron con que el empleo de estos materiales es adecuado y fiable en clínica ${ }^{4}$. Estos datos han hecho posible el tratamiento con carillas de porcelana como una forma eficaz y segura para conseguir y mejorar la estética del sector anterior en pacientes preocupados y necesitados de ello. En Inglaterra se cifra en torno a más de 100.000 carillas cerámicas al año, el número de unidades que se instalan en la boca de los pacientes 5 . Su alta predecibilidad y su elevado porcentaje de éxitos, que se cifra en torno al $99 \%$ a los 5 años ${ }^{6 *}$, permiten ofrecer una alternativa terapéutica muy satisfactoria, con un porcentaje de éxito alrededor del 97\%a los 15 años $^{7 * *}$. Cuando se incluyen los fracasos estéticos en la estadística se elevan algo los porcentajes de fracaso ${ }^{7 *}$. Por el contrario, Crispin ${ }^{8}$ defiende que es necesaria una mayor investigación aún, antes de preconizar el uso masivo de cerámica para frentes laminados e «nnlays-onlays» en lugar de restauraciones de composite.

Una carilla de cerámica consiste en una lámina de porcelana que recubre parcialmente un diente, a modo de veneer, al que se une por medios micromecánicos adhesivos, tras el grabado del esmalte. La adhesión de las carillas de porcelana al diente se consigue mediante el concurso de cuatro elementos principales, a saber ${ }^{9 * *}$ : a. La carilla de porcelana propiamente dicha, grabada en su cara interna, aquélla que se enfrentará a la superficie dentaria.

b. El diente al que irá destinada la carilla, que estará acondicionado en su superficie adamantina.

c. Un elemento químico silánico como elemento de acondicionamiento y unión entre la carilla de porcelana y el cemento de composite.

d. Un cemento de composite, que servirá de interfase entre el diente dentaria preparada y la veneer cerámica.

Aparte de sus ventajas estéticas sobre los composites las nuevas porcelanas son muy resistentes, con una dureza similar o incluso superior a la del esmalte. En esta línea vamos a hacer una descripción de las ventajas y desventajas de las carillas de porcelana frente a las carillas de composite y a los retenedores de recubrimiento total.

$$
\text { Ventajas }
$$

1. Técnica de dificultad media. Las destrezas y habilidades necesarias para poder llevar a cabo un tratamiento por medio de carillas de porcelana son asequibles a todos los odontoestomatólogos con un entrenamiento de dificultad media, en relación a la mayor facilidad del composite y dificultad de la corona.

2. Preparación dentaria muy conservadora. La cantidad de estructura dentaria a eliminar para conformar un diente como receptor de una carilla de porcelana es escasa en comparación con la preparación necesaria para una corona de recubrimiento total. En los casos menos conservadores se elimina en torno al 30\% de la estructura dentaria. Esto es de 2,4 a 4,3 veces menos que para una corona de recubrimiento total ${ }^{10}$.

3. Estética muy elevada. La ausencia de metal en la preparación protésica junto con el grosor de la cerámica empleada permite una transmisión óptima de la luz, que se va a reflejar en la dentina subyacente de manera similar a la del diente sano. El resultado estético es óptimo. Su color parece natural y es estable a largo plazo pues no se altera por ninguna circunstancia mientras no se fracture. Por otro lado, el color es parcialmente modificable si empleamos maquillajes cerámicos o bien tintes internos incorporados al composite cementante.

4. Resistencia elevada a las fuerzas. Una vez cementadas son capaces de soportar fuerzas de tracción, tensión y cizalla importantes pues la adhesión que consiguen al esmalte es eleva$\mathrm{da}^{7 * *}$.

5. Biocompatibilidad local y general: de todos los materiales de recubrimiento dental que poseemos, la cerámica es junto con el oro, el que menos reacciones biológicas desencadena. Su superficie lisa no retiene placa.

6. Resistencia al desgaste. Las fuerzas oclusales y de masticación no las desgastan, aunque puedan llegar a fracturarlas.

7. Resistencia a la tinción. La superficie glaseada no permite la incrustación de tinciones, al no presentar microporosidad. Este glaseado permite el mantenimiento del brillo superficial durante todo el tiempo de vida de las carillas. Sólo en la interfase de cemento pueden formarse tinciones con el tiempo. 
8. Resistencia al ataque químico. Diferentes sustancias químicas, como ácidos (cítrico y otros), disolventes (alcohol), medicaciones (antibióticos) y cosméticos (colutorios) pueden producir alteraciones tanto en el esmalte dentario como en las carillas de composite. Sin embargo las carillas de porcelana son inalterables ante estas agresiones.

9. Radiopacidad. Su densidad las hace similares al esmalte en cuanto a la penetrabilidad por los rayos $X$ Esto permite que el diente situado por debajo sea asequible a la exploración radiográfica, aún recubierto por la carilla.

10. Costo aceptable. Los costes y los tiempos de tratamiento son inferiores a los de coronas de recubrimiento total

\section{Inconvenientes}

1. Técnica clínica más compleja que para las carillas de composite y mucho más que para una corona. Requiere varias sesiones clínicas.

2. Técnica de laboratorio compleja. El laboratorio dental necesita llevar a cabo técnicas de gran precisión para lograr un ajuste exacto de la carilla. Los márgenes son lugares de gran dificultad para su ajuste. Además deben ser muy delgadas, y en consecuencia muy frágiles.

3. Fragilidad relativa. La construcción de finas láminas de porcelana da una fragilidad inherente a las carillas lo que hace que, con alguna frecuencia, se produzcan fracturas de las mismas. Una vez cementadas esta fragilidad se atenúa grandemente.

4. Dificultad para la reparación. La carilla fracturada es de difícil repara- ción, aunque en ocasiones se puede llevar a cabo. El problema es que, con el tiempo aparecen tinciones, en la interfase reparada.

5. Técnica adhesiva compleja. La técnica de adhesión es muy minuciosa y requiere una preparación importante, que consume tiempo y esfuerzos en un grado muy superior al del cementado no adhesivo de las coronas de recubrimiento total.

6. Tratamiento irreversible: una vez tallado el diente no lo podemos recuperar, aunque su invasión sea mínima.

7. Imposibilidad de cambiar el color una vez cementada la carilla.

\section{Indicaciones}

Las principales indicaciones de las carillas de porcelana son problemas estéticos de una u otra etiología, aunque también pueden tener indicaciones para solucionar algunas alteraciones anatómicas y funcionales. En estos dos supuestos, hemos de decir que los mejores resultados se consiguen con coronas de recubrimiento total.

\section{Estéticas}

a. Cambios de coloración dentaria: las discromías y tinciones intrínsecas (tetraciclinas, fluorosis, dientes desvitalizados, tinción por amalgama, envejecimiento natural, etc.) pueden ser modificadas por medio de carillas de porcelana. Cuanto más intensa sea la coloración patológica más profundo será necesario tallar el diente, para poder enmascarar el color.

b. Cambios de posición dentaria: Dentro de unos límites se pueden recolocar dientes con rotaciones por medio de carillas de porcelana que los coloquen en una posición más ideal; ello obligará en la mayoría de los casos a tallados dentarios que se salen de la ortodoxia, en función de la posición y/o rotación del diente

c. Cambios en la textura superficial dentaria. En ocasiones, el esmalte presenta una rugosidad excesiva, u oquedades que retienen placa con la consiguiente facilidad de tinción. La colocación de carillas de porcelana que restauren una anatomía lisa superficial conlleva la corrección anatómica y la no retención de placa bacteriana, solucionando así el problema.

d. Cierre de diastemas. El ensanchamiento del diente por medio de carillas permitirá el cierre de pequeños espacios interdentarios de un modo conservador. No aconsejable si superan $1 \mathrm{~mm}$ de anchura.

\section{Anatómicas}

La indicación de carillas para solucionar anomalías de forma, tamaño o volumen dentario, tanto congénitos como adquirido debe tomarse con cierta reserva. No obstante, cualquiera de ellos, siempre y cuando sean de pequeña intensidad/severidad podría ser restaurada con carillas sin perjuicio de otro tipo de tratamientos como coronas de recubrimiento total, en principio más adecuadas. Así podrían solucionarse tanto anomalías congénitas (hipoplasias del esmalte, microdoncias y dientes conoideos, etc.) como adquiridas (fracturas, atriciones, abrasiones, etc.) e incluso las ocasionadas por trastornos alimentarios (bulimias, etc.) con el fin de reponer la estructura dentaria perdida por la erosión ocasionada por los vómitos/regurgitaciones repetitivas de estos pacientes. 


\section{Funcionales}

Al igual que en las indicaciones anatómicas y con las mismas limitaciones, las carillas de porcelana pueden solucionar alteraciones funcionales tales como restauración de las guías anterior y canina colocándolas sobre la cara palatina de los dientes anterosuperiores, más que a expensas de la cara vestibular de los inferiores.

\section{Otras indicaciones}

Otra posible indicación de las carillas de porcelana es la restauración de problemas derivados de la porcelana de una corona metal-cerámica, bien por fractura de la porcelana, por necesidad de modificar su color, modificar su morfología u otras. Debido a que las carillas de porcelana pueden unirse a la cerámica de la corona metal-cerámica por medios adhesivos micromecánicos y químicos de suficiente resistencia físico-mecánica. No obstante, estas indicaciones tienen sus limitaciones centradas en el espacio suficiente y no sobrecontorneado del diente.

\section{Contraindicaciones}

Aunque las carillas pueden solucionar muchos problemas, no están exentas de contraindicaciones derivadas de su fragilidad y facilidad de descementación, tanto más cuanto no se siga una técnica e indicación rigurosa.

\section{Estéticas}

Alteraciones muy importantes del color dentario pueden ser imposibles de esconder de manera suficiente con las carillas de porcelana pues su transparencia hace muy difícil el total enmasacaramiento de la discromía, incluso si se usan opacificadores y se incrementa el grosor al máximo permitido.

\section{Funcionales}

Las situaciones de carga excesiva sobre las carillas de porcelana o sobre los dientes soporte de las mismas causarán fuerzas inadecuadas que redundarán en la fractura o descementado de la carilla. Entre estas situaciones de sobrecarga habremos de citar el bruxismo y los hábitos parafuncionales, que pueden causar fracturas y descementados continuos. En esta línea, un caso particular es el formado por un diente antagonista de un implante. Durante la función, normal o parafuncional, el resto de la dentición natural se intruirá con lo que el diente antagonista sufrirá toda la carga. Si es portador de una carilla, la fatiga acabará con ella o con su cemento.

\section{Otras}

Hábitos inadecuados, higiene insuficiente o elevado índice de caries son otras importantes contraindicaciones

a. Hábitos inadecuados tales como el mordisqueo de bolígrafos, la onicofagia, la sujeción de clavos y objetos con los dientes y cualquier otro que implique una actividad dentaria incorrecta contraindicará el empleo de carillas de porcelana como método restaurador, por el incremento del riesgo de fracturas.

b. Higiene insuficiente. El acúmulo de placa bacteriana sobre la interfase diente/restauración cerámica conducirá a la tinción de la misma con la consiguiente alteración estética.

c. Un índice de caries elevado, asociado o no a higiene insuficiente hace aparecer caries con mayor facilidad en la interfase cementante, elevando los riesgos de fracaso.

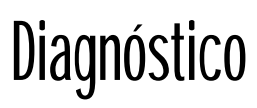

Aunque diagnóstico y planificación de un tratamiento con carillas no reúnen la especial importancia que tendrán en cualquier otro tratamiento protésico, no es menos cierto que deben abordarse integralmente, teniendo en cuenta todos los parámetros que habitualmente se investigan en los tratamientos protésicos. Así, el diagnóstico debería comprender una exploración intra y extraoral completa con evaluación y registro del estado periodontal, fotografías de la situación dentaria y modelos diagnósticos del paciente. Es necesaria una evaluación radiográfica completa, por medio de ortopantomografía y sobre todo radiografías periapicales de, por lo menos, cada uno de los dientes que se van a recubrir con las carillas.

Por otro lado, se han de documentar minuciosamente todos los detalles presentes en la dentición del paciente, especialmente en lo que se refiere al color, con esquemas dibujados sobre las características de distribución del mismo, la presencia de tinciones y cualquier otra marca sobre el diente. Aparte de la inspección, la fotografía es el mejor medio para el registro objetivo de la situación dentaria del paciente. Se hacen fotografías extraorales, para recoger la sonrisa del paciente en su conjunto, y vistas frontal, lateral, a boca entreabierta, y a boca cerrada. Intraoralmente se tomarán fotografías de ambas arcadas dentarias, junto con cualquier 
particularidad de los dientes que consideremos de interés.

Puede ser muy útil la grabación de imágenes, mientras el paciente realiza algún tipo de declaración ante la cámara. De este modo se podrá evaluar la relación funcional dentolabial.

El registro y análisis de la oclusión estática y dinámica, tanto intraoralmente como en los modelos de estudio montados en articulador, para analizar las relaciones que los dientes contraen, tanto en posición estática como en las excursivas mandibulares es otra de las exploraciones necesarias.

El encerado de estudio es de gran ayuda para evaluar con antelación qué necesidades de tallado se van a plantear y qué resultado podemos obtener. Se deben seguir pautas que relacionen el tamaño y forma adecuados de los dientes con las características morfotípicas del paciente, en cuanto a anatomía facial, criterios de arquitectura gingival y sobre todo de línea de sonrisa ${ }^{11^{* *}}$.

\section{Acciones necesarias}

\section{para complementar el diagnóstico}

a. Comunicación con el paciente: es necesario evaluar la personalidad y actitud del paciente junto con sus expectativas de resultados, como elemento necesario para el éxito del tratamiento. Un paciente cuyas expectativas sean poco realistas, o que presente una situación dentaria que no pueda ser suficientemente mejorada con carillas, será una contraindicación para este tipo de tratamiento. Es por eso que tras el diagnóstico es necesario explicar al paciente los objetivos de tratamiento y los resultados esperables. Los tratamientos que afecten a la estética están influenciados por la percepción individual de la misma, lo que los convierte en fuente de riesgo de fracaso, ya que no siempre lo que le gusta al dentista es lo que le gusta al paciente $e^{7 * *}$.

Hay que comunicarle la necesidad de tallado con eliminación irreversible de estructura dentaria y hacerle comprender los riesgos: posibles pulpitis y tratamiento de conductos, entre otros; el riesgo es remoto, pero existe y es el paciente el que debe asumirlo. Es necesario explicarle los riesgos de fracaso del tratamiento, expuestos al inicio de este capítulo. Hay que hablarle en porcentajes de fracaso a lo largo del tiempo y hay que asegurarse de que lo ha comprendido. Para esto se le entregará para su lectura un consentimiento informado, con todos los ítems susceptibles de complicaciones, varios días antes de su tratamiento. El tratamiento se iniciará después de que el paciente haya firmado el permiso.

\section{b. Encerado de estudio y carillas} provisionales. Como todo tratamiento invasivo, que requiera una alteración irreversible de la estructura dentaria, es necesario aportar al paciente toda la información posible previamente al comienzo del mismo. Los tratamientos con coronas de recubrimiento total permiten la ejecución de coronas provisionales, modificables hasta encontrar aquella situación con la que el paciente se encuentra más a gusto. Esto no es posible con las carillas de cerámica, por lo que es conveniente tratar de lograr que el paciente pueda «ver» el resultado final con antelación a que éste esté realizado.

El procedimiento es como sigue: sobre los modelos de diagnóstico montados en el articulador semiajustable se hace un encerado de estudio que representa el resultado final esperado. Este encerado tendrá una doble función: por un lado se mostrará al paciente para que observe, a grosso modo, el resultado de sus carillas y por otro servirá para la construcción de las carillas provisionales en composite o acrílico.

Sobre este encerado se construye una llave de silicona pesada que contornee las superficies vestibulares de los dientes a tratar. Esta llave, cortada en secciones horizontales, en «varias rodajas» desde incisal a gingival, servirá de referencia y guía que permitirá modelar carillas transicionales con composite sobre la superficie de los dientes a tratar ${ }^{12^{*}}$. Las rodajas no se separan completamente, sino que permanecen unidas en uno de los extremos de la llave de silicona, situado distal al área de trabajo. Esto permite desplegar las rodajas entre sí, a modo de abanico, de manera que se puede explorar todas las superficies dentarias situadas bajo los segmentos horizontales de la llave de silicona. Ahora se pueden construir unas carillas provisionales según el encerado de estudio. Una vez construidas y adheridas las carillas provisionales a las superficies labiales de los dientes, permitirán al paciente ver in situ, el resultado final esperable para sus dientes, con las modificaciones de forma $y$ tamaño que se le van a realizar. Es conveniente -pero no imprescindible-, que el paciente pueda llevarlas durante al menos una semana, tiempo necesario para que olvide su 
engrama de sonrisa y vaya aceptando su nueva situación.

Esta ayuda diagnóstica es adecuada cuando el volumen final a obtener sea mayor que el inicial, es decir, en casos en los que haya que aumentar el volumen dentario, como ocurre en las microdoncias $u$ otras alteraciones de forma y volumen dentarios, en los cierres de diastemas o en modificaciones de la posición dentaria por dientes lingualizados o rotados. Por el contrario, esto no es posible cuando no haya que tallar volumen dentario, como suele ocurrir en las discromías y alteraciones del color. En este caso, la falta de visualización previa queda compensada por la impresión favorable del cambio de coloración tras el tratamiento.

En casos extremos, será necesario proceder a tratar el diente con una reducción parcial de volumen, seguido de la toma de impresiones sobre la que el laboratorio confeccionará unas carillas de resina/acrílico provisionales con estratificación de color. El paciente portará estos provisionales que podrán recibir sucesivas modificaciones en el tamaño y la forma hasta que el paciente dé su visto bueno. En este momento se confeccionará la llave de silicona que dará al ceramista del laboratorio las indicaciones precisas de forma vestibular, y al protesista las indicaciones precisas de profundidad del tallado.

\section{Técnica y sistemática clínica}

La sistemática clínica comprende, en general, como en cualquier restauración protésica, los siguientes apartados: reducción vestibular, impresio- nes, colocación de provisionales si procede, pruebas, cementado e instrucciones y consejos de uso finales.

\section{Reducción dentaria}

1. Sin reducción dentaria. En aquellos casos en los que la indicación de carillas sea por la necesidad de lograr un cambio volumétrico o morfológico del diente, como puede ser el posicionamiento lingual o palatino de un diente, buscando un efecto visual de alineamiento con los dientes vecinos, o bien en casos de rotación, microdoncia o dientes conoideos, no será necesario efectuar reducción alguna, salvo un pequeño tallado para rectificar levemente la línea de inserción, eliminando sobrecontorneados 0 retenciones naturales, perfilar el margen o dejar expuesto el esmalte para la retención.

2. Con reducción dentaria. Sin embargo, en la mayoría de casos será necesario tallar la cara vestibular del diente, porque si no el caso podrá finalizar con un sobrecontorneado intolerable, o con un espesor de cerámica insuficiente para asegurar la resistencia de la carilla o el enmascaramiento de la tinción. No obstante la reducción será lo más conservadora posible, compatible con el aspecto final del diente, grosor y resistencia de la carilla y adhesión recordando que, por lo menos, el 50\%de la superficie tiene que ser esmalte para lograr una buena adhesión. Para lograr que la reducción sea la mínima es de gran ayuda hacer previamente un encerado de estudio seguido de una llave de silicona que sirva siempre de referen- cia para controlar la profundidad del tallado.

No existe uniformidad entre los autores que han comunicado técnicas de reducción dentaria para recibir carillas, y presentan ligeras variaciones de

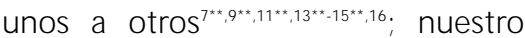
objetivo es presentar una técnica amalgamadora de los diferentes criterios, y para esto hablaremos de reducción estándar y reducción no estándar.

\section{Reducción estándar}

La reducción estándar comprende el control de los siguientes apartados: reducción o tallado vestibular, reducción proximal, reducción del margen y borde incisal, maniobras finales

La reducción estándar inicial varía de 0,5 a $0,7 \mathrm{~mm}$ de profundidad, con un mínimo de $0,3 \mathrm{~mm}$, para la zona axial del diente, llegando a 1,5 mm en el borde incisal.

\subsection{Reducción o tallado vestibular}

El tallado de la cara vestibular para lograr una profundidad entre 0,5 y 0,8 $\mathrm{mm}$ con un mínimo de $0,3 \mathrm{~mm}$ -dependiendo de la zona del diente o de la necesidad de un mayor grosor de la carilla o incremento del diente a expensas de la porcelana de la carilla-, se realiza de preferencia con una piedra diamantada troncónica de extremos redondeados, de grano grueso, de longitud y calibre adecuados.

En cada plano de la cara vestibular de los incisivos centrales o laterales (la mitad o 2/3 incisales de esta cara constituye un plano, el resto otro de diferente orientación) se tallan 304 surcos de orientación verticales, sensiblemente paralelos al eje mayor del diente, de la profundidad deseada 

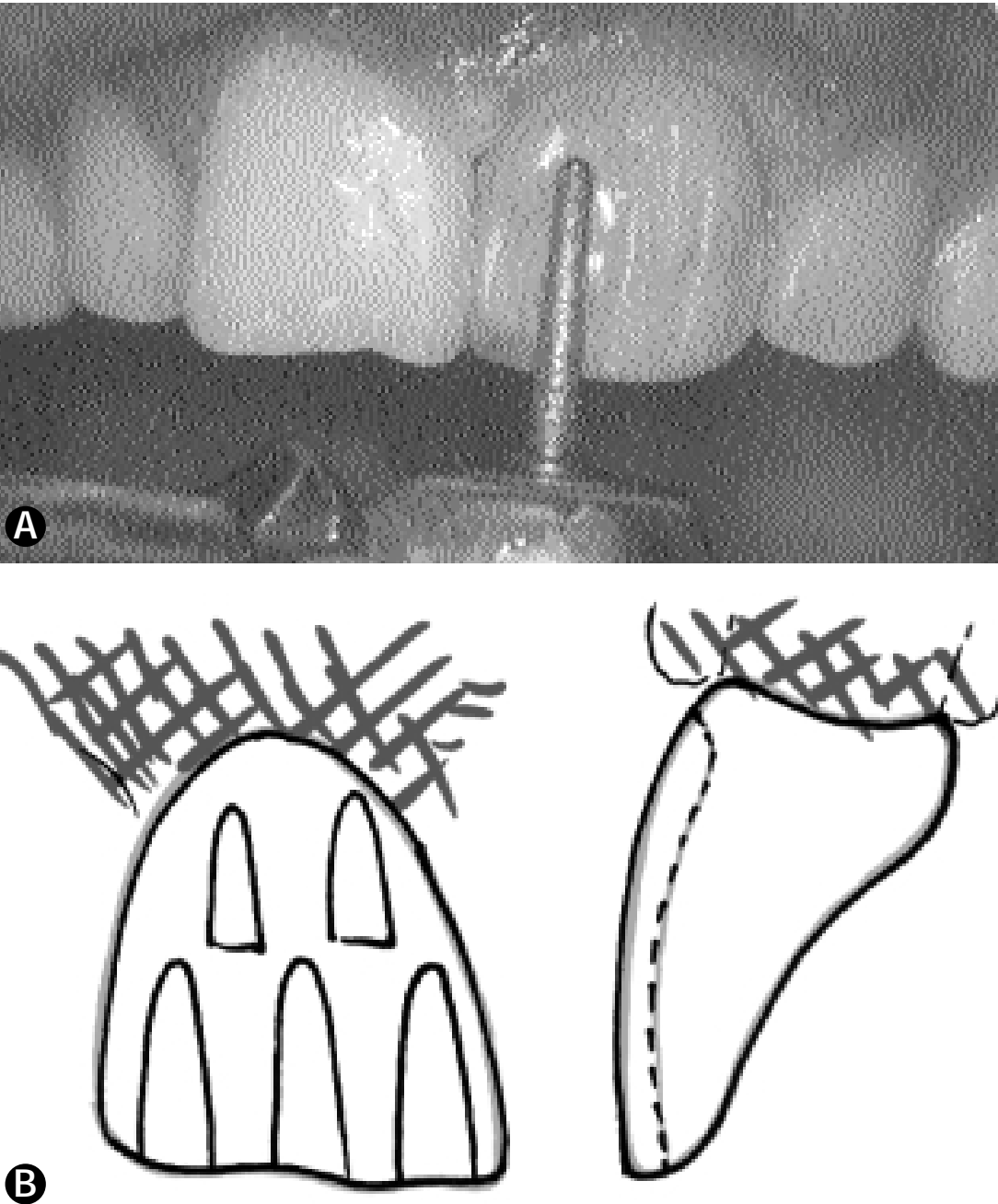

Figuras la y b. Surcos de orientación y profundidad verticales, diamantado troncocónico.

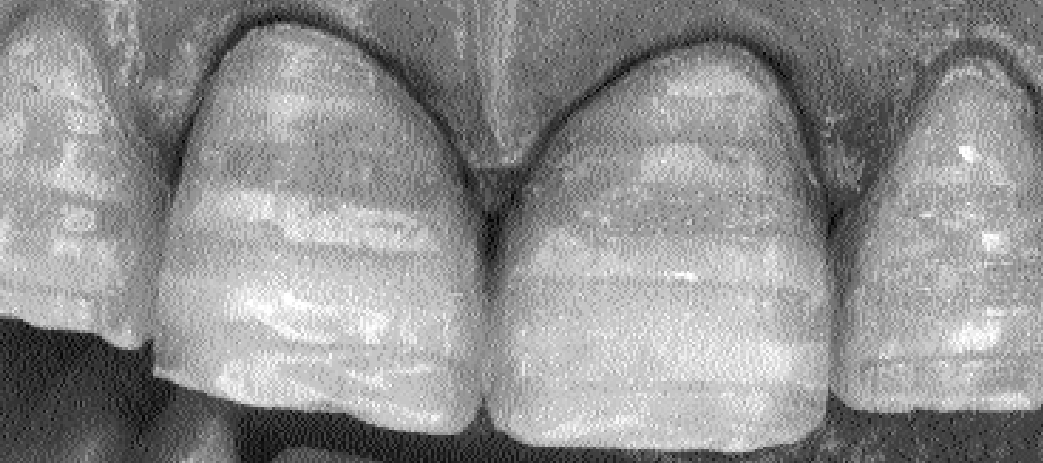

Figura 2. Surcos de orientación y profundidad horizontales, diamantado de ruedas. colocando la piedra diamantada paralela al plano en cuestión, y sin que coincidan los surcos de un plano con los del otro (fig. la y b).

Ahora se continúa eliminando el esmalte entre los surcos procurando una reducción uniforme, sin socavados ni ángulos diedros agudos. Esto ha de ser especialmente así en la zona de transición entre los dos planos, que tiene que verse redondeados en perfecta continuidad. Para controlar la profundidad del tallado deseado es de gran ayuda, aparte del diámetro de la piedra diamantada elegida, pincelar la cara vestibular del diente, con un rotulador indeleble: esto dará una mejor referencia visual de la profundidad de los surcos que estamos realizando. Los surcos de orientación también pueden efectuarse con piedras esféricas de diamante de grano grueso del diámetro adecuado $(0,3,0,5-0,8)$ que se penetran en su totalidad en el esmalte. También se pueden emplear piedras diamantadas especiales para tallar carillas, con 3 o 4 ruedas diamantadas en su tallo. Con ellas se traza en la superficie vestibular tres o cuatro marcas paralelas al borde incisal, moviendo la fresa en sentido mesiodistal, a la profundidad deseada (fig. 2). La de mayor diámetro $-0,5 \mathrm{~mm}-$, se usa cuando el espesor adamantino lo permite, lo que ocurre en los incisivos centrales y caninos superiores; la profundidad menor $-0,3 \mathrm{~mm}-$, se emplea en los dientes laterales y en los incisivos inferiores, así como en la porción más gingival de los centrales superiores.

Con ambos métodos de reducción axial, ya sea vertical u horizontal, es necesario adaptar la inclinación del 


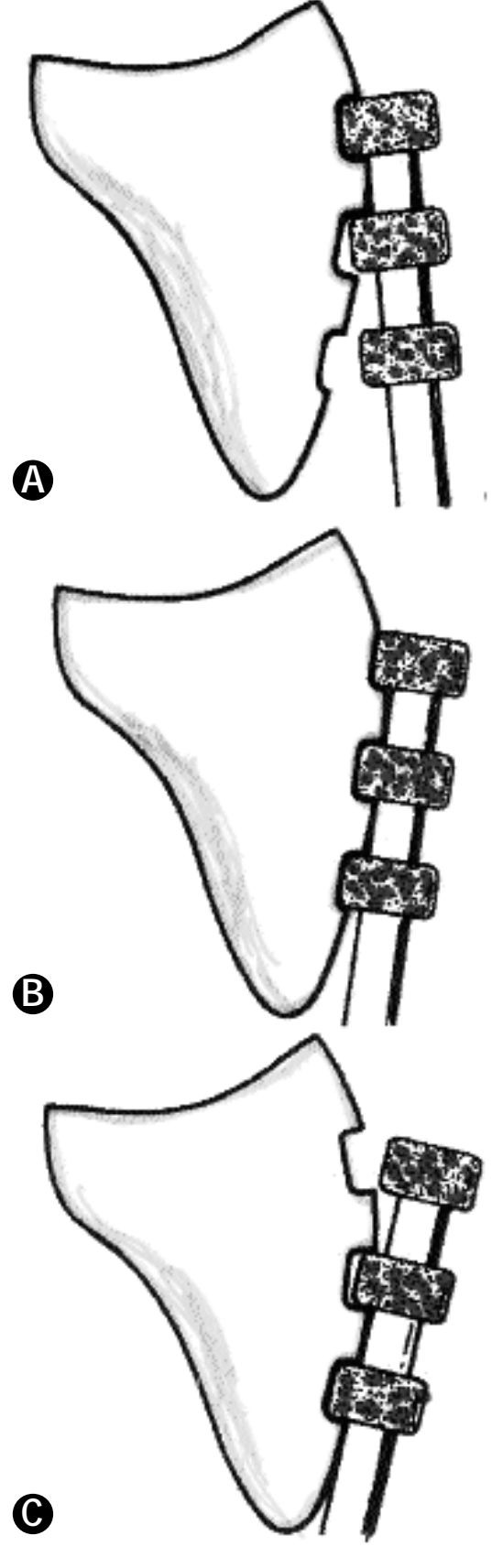

Figuras $3 a, b$ y c. El tallo de la fresa se paraleliza a la superficie de la cara vestibular.

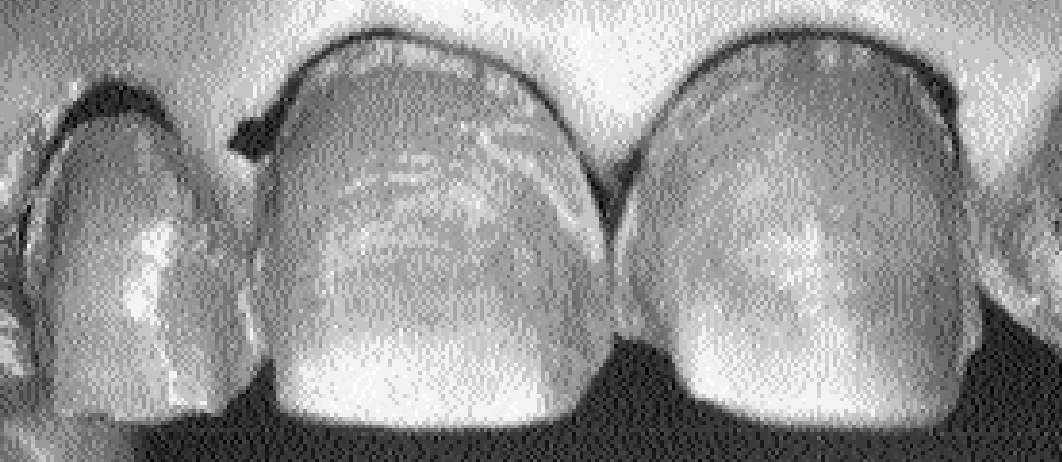

Figura 4. Reducción proximal con márgenes en áreas no visibles.
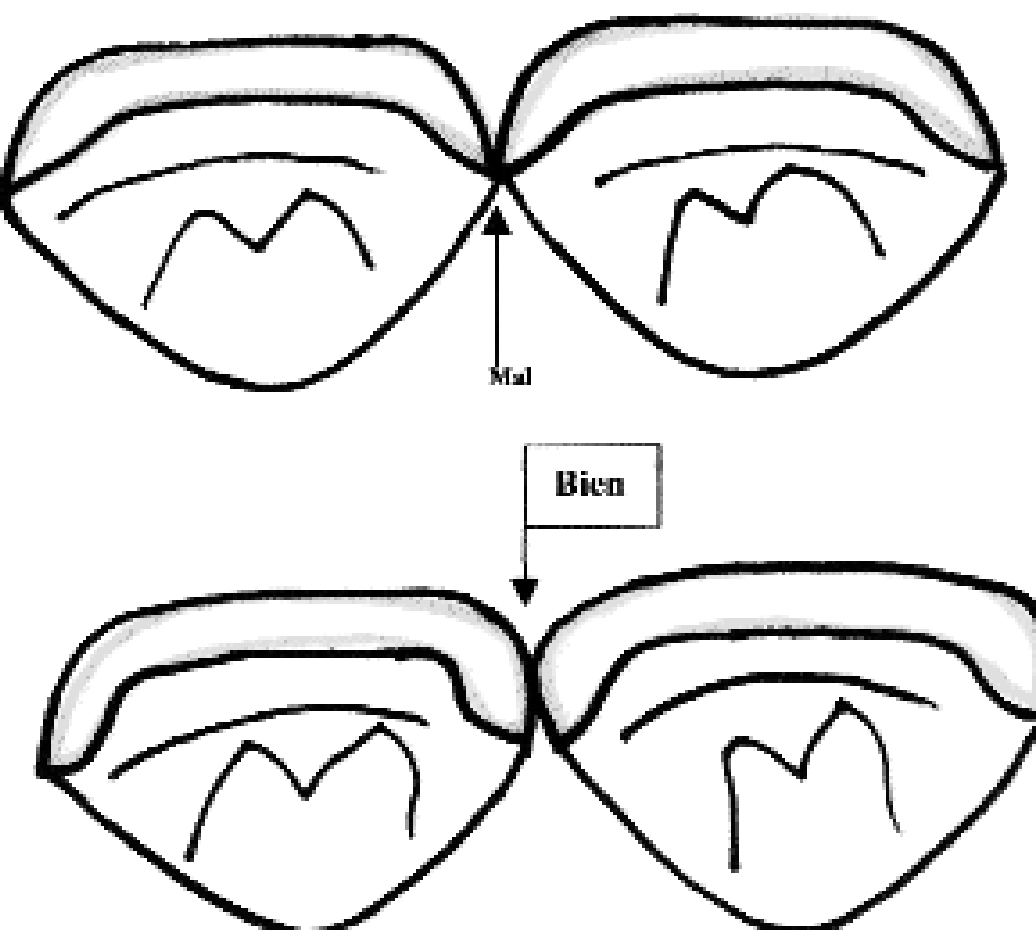

Figura 5. Ubicación del punto de contacto en cerámica entre carillas. NO se coloca en la interfase cementante.

tallo de la piedra diamantada a las convexidades del diente tratado. Así se mantendrán las profundidades del tallado de manera uniforme, sin excesos que contribuyan a eliminar el esmalte (fig. 3a, b y c).

\subsection{Reducción proximal}

El tallado de las caras proximales mesial y distal ha quedado esbozado al hacer la reducción vestibular y sólo hay que tener en cuenta que esta reducción proximal debe extenderse hacia palatino/lingual hasta las zonas no visibles del diente (fig.4). El perfilado y acabado de esta reducción proximal es en chaflán curvo o chamfer realizado con el extremo redondeado 

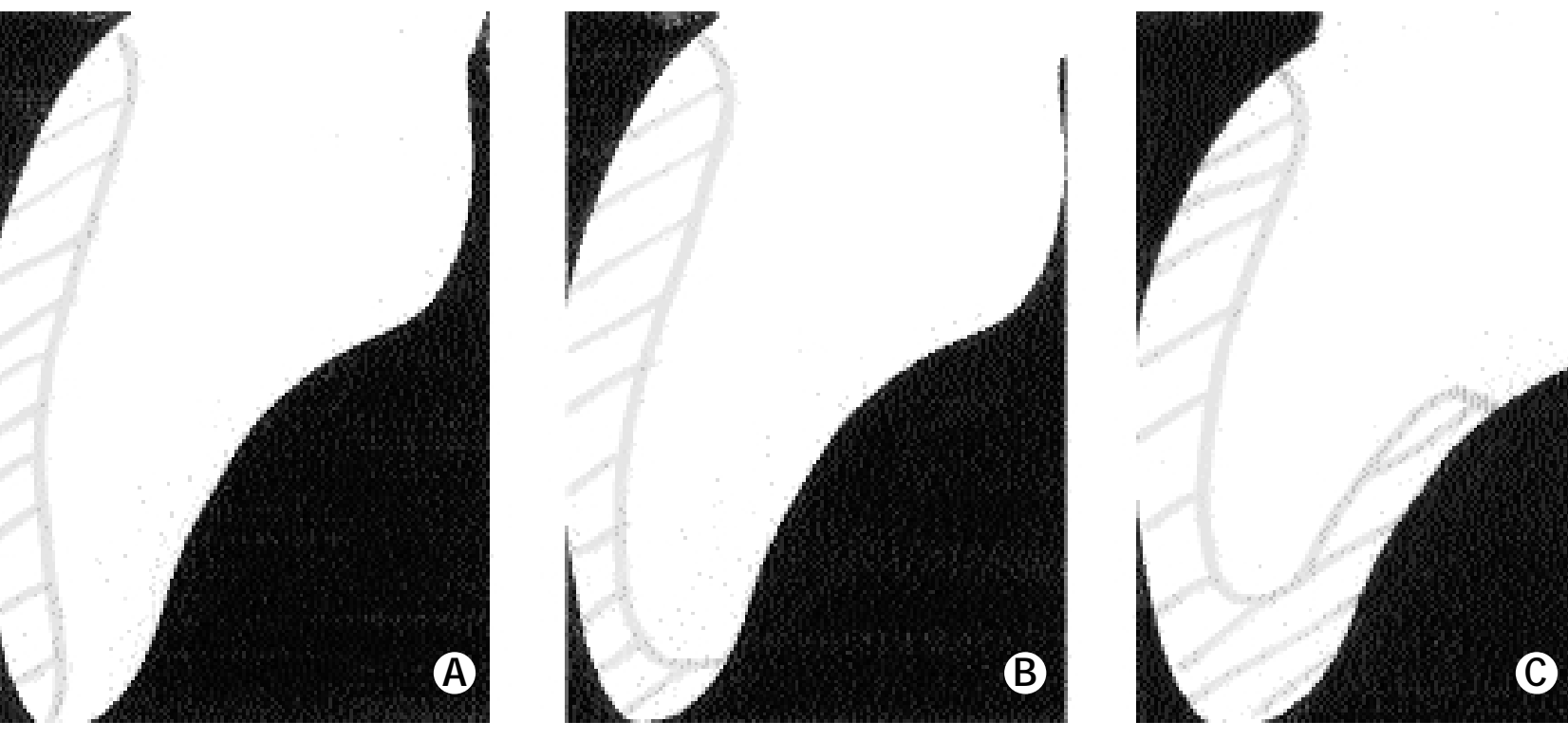

Figura 6. Acabado del margen incisal de la preparación. A. Acabado en el propio borde incisal del diente. B. Acabado en el 1/3 incisal de la cara palatina del diente. C. Acabado con gran cobertura palatina del diente

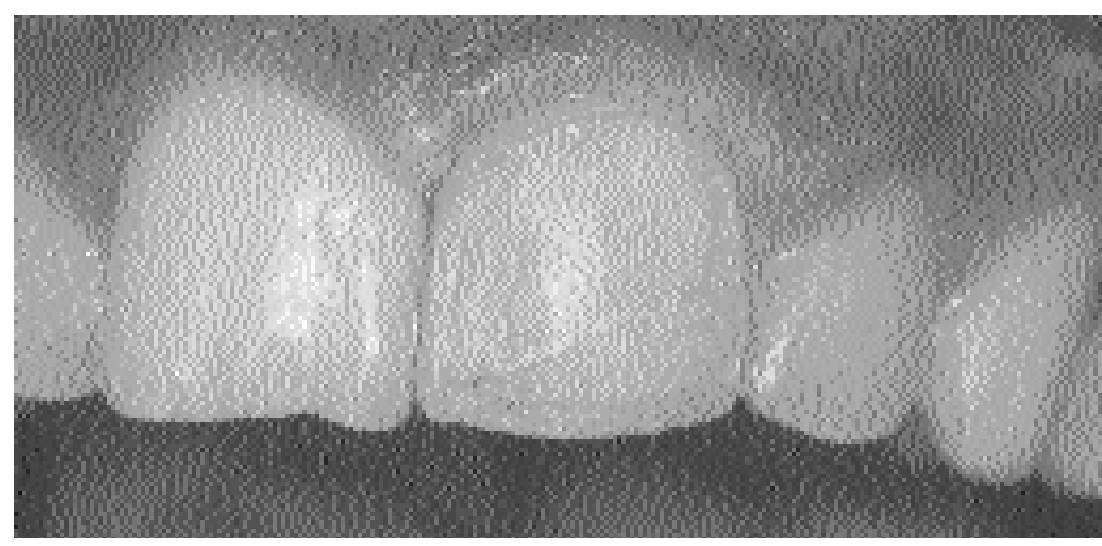

Figura 7. Finalización del margen incisal en el mismo borde incisal dentario.

de la piedra diamantada tronco-cónica procurando que el ángulo que se forme con la cara proximal sea igual o mayor de 90․

En casos de diastemas en los que hay que crear un área de contacto o discromías intensas en las que cualquier exposición del diente, por pequeña que sea, va a ser muy llama- tivo para el ojo humano, la reducción normal se extiende hacia palatino obviando el punto de contacto interproximal. El nuevo punto de contacto debe procurarse entre diente/cerámica o cerámica/cerámica, sin ninguna relación con la interfase cementante, para evitar su deterioro prematuro (fig. 5).

\subsection{Reducción o terminación incisal}

Borde Incisal. Para la preparación dentaria incisal de las carillas se puede optar por dos posibilidades: o bien finalizar en el borde incisal propiamente dicho o bien a nivel de la cara lingual o palatina del diente (fig. 6a, b y c). La finalización en el borde incisal puede a su vez abarcar dos modalidades; en una termina en la mitad vestibular de dicho borde cuando éste tiene suficiente anchura y grosor (cfra. fig. 6a) o bien no es necesario reducirlo (fig.7). En la otra abarca toda la anchura del borde incisal incluso contorneando ligeramente el mismo. En ambas situaciones la reducción se efectúa con el extremo redondeado de la piedra troncocónica de diamante de grano grueso, de tal modo que el aspecto final del borde incisal sea de chaflán curvo que se prolonga sin solución de continuidad con el margen de las caras proximales (fig. 8). 


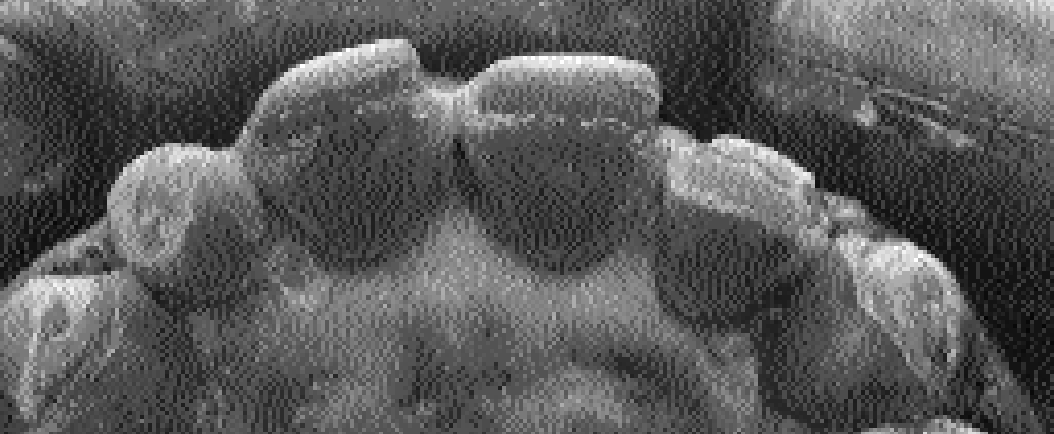

Figura 8. Finalización del margen incisal contorneando el borde incisal del diente.

En aquellos casos en los que el borde incisal está afectado por cualquier causa, y hay que prepararlo $o$ reconstruirlo, o bien hay que aumentar la longitud del diente $1 \mathrm{~mm} o$ algo más, la carilla recubre el borde incisal finalizando en el 1/3 incisal de la cara palatina del diente, (fig. 6b) lejos del área de contacto oclusal con el antagonista que hay que comprobar previamente. La terminación palatina/lingual reduce la posibilidad de fracturas y de desprendimiento de las carillas.

Con la fresa acostumbrada se hacen reducciones de 1-1,5 $\mathrm{mm}$ de profundidad en el borde incisal (fig.

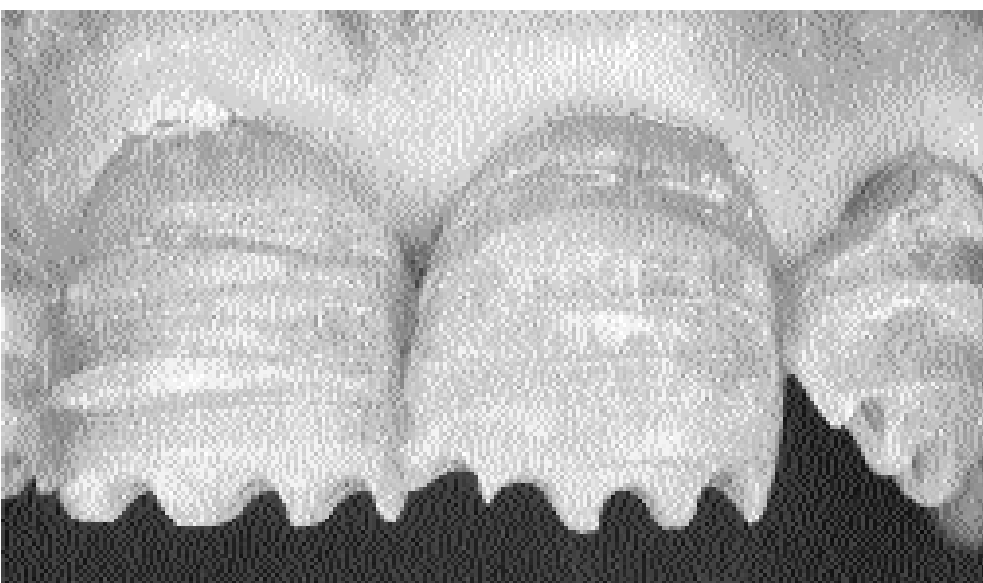

Figura 10. Reducción clinica del borde incisal.
9), si es necesario (fig. 10) aunque pueden obviarse cuando hay que alargar el diente. A continuación se elimina la estructura dentaria intersurcos colocando la piedra diamantada inclinada hacia palatino en los superiores y hacia vestibular en los inferiores, unos 45․ Con la misma fresa se extiende la reducción hacia palatino/lingual logrando la profundidad adecuada, y una terminación en chaflán curvo que se continúa con el margen de las caras proximales. No hay que olvidarse de redondear los ángulos y todas las aristas (fig. 9). Se consigue así una geometría y un grosor de cerámica suficiente para resistir la concentración de fuerzas sobre la carilla. No obstante, la reducción incisal no debe ser tan profunda como para que se fracture la cerámica por grosor excesivo sin soporte dentario, provocado por el contacto del diente antagonista.

\subsection{Reducción gingival}

El margen gingival se sitúa en el esmalte y no en el cemento siempre que sea posible. La excepción a esta regla es la presencia de recesión gingival con exposición radicular, en cuyo caso será necesario ubicarlo en el cemento; esto requerirá una adaptación muy precisa de la carilla a dicho margen para minimizar los problemas derivados de una interfase poco resistente (figs. 11a y b).

En cuanto a la situación de altura respecto a la encía marginal, el margen puede finalizar yuxta, supra o subgingivalmente.

El margen yuxtagingival es el ideal, pues no invade el surco gingival ni el espacio biológico. Permite siempre buena estética y una mejor visión y facilidad para el tallado y la toma de

RCOE, 2003, Vol 8, №6, 647-668 

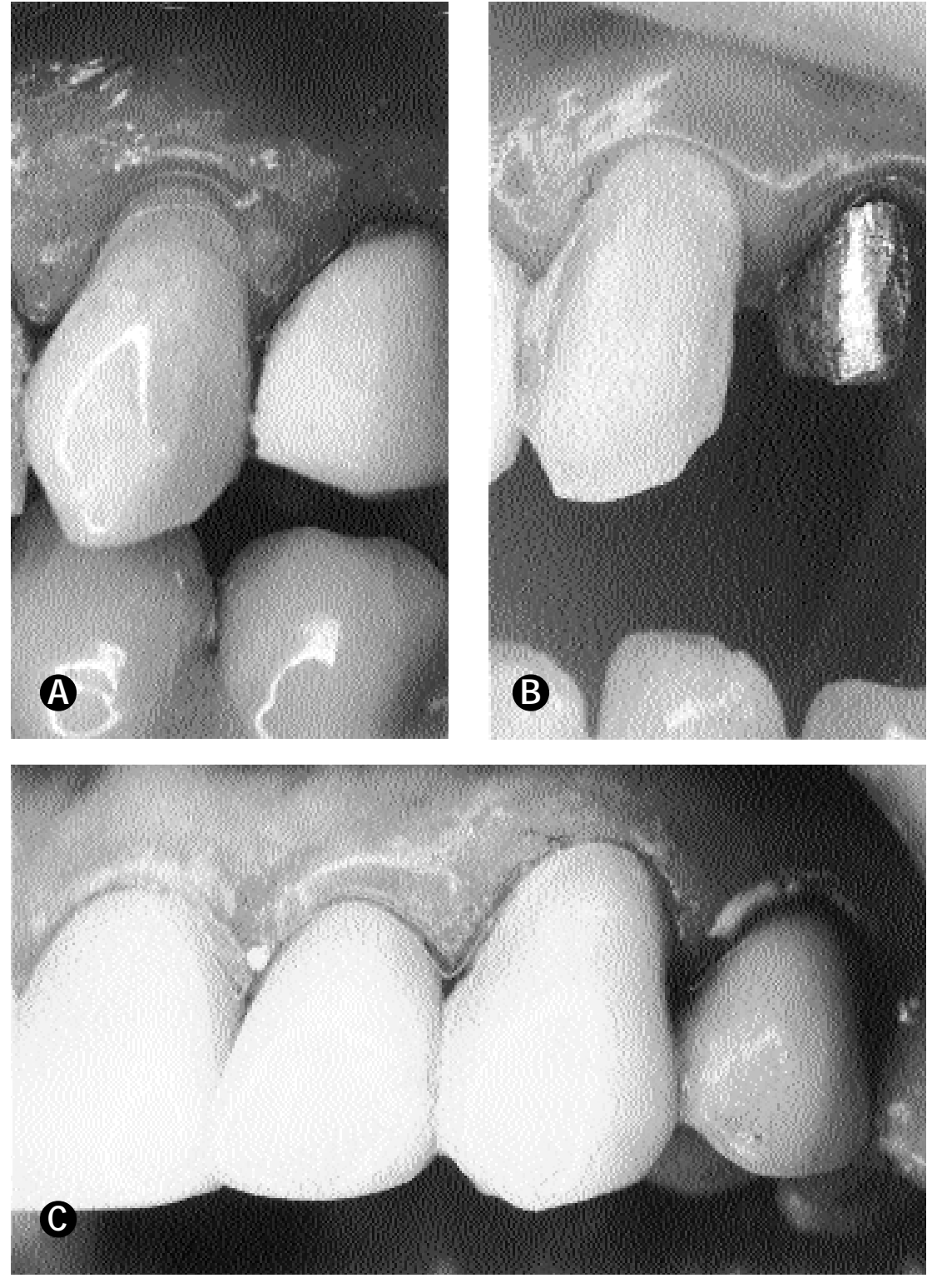

Figura 11. A. Canino con recesión gingival. B. Preparación del margen gingival hasta el cemento radicular, para enmascarar la recesión. $C$. Carilla recién cementada, con margen yuxtagingival para enmascarar la recesión.

impresiones. Es de elección siempre y cuando no existan alteraciones importantes del color entre el diente y la carilla, que puedan apreciarse después del cementado.

En ocasiones puede situarse supra- gingivalmente, fuera del surco, a una distancia lejana de la encía. Así puede indicarse cuando la línea de sonrisa es baja, y el paciente no enseña dicho margen por mucho que sonría. Un margen supragingival siempre es antiestético por lo que es conveniente cuando no haya grandes diferencias de color entre el diente y la carilla. En este caso, el paciente observará una terminación brusca de la misma, y podrá mostrarse crítico con la restauración (fig. 12).

El margen ligeramente subgingival es de elección cuando se indica la carilla para ocultar alteraciones del color dentario pues la presencia de una mínima cantidad de diente discrómico supragingival llamará poderosamente la atención con el consiguiente rechazo (fig.13). No obstante, la invasión del surco debe ser mínima, no mayor de 0,5 mm, y siempre conservando una anchura biológica igual o mayor de $2 \mathrm{~mm}$. Además, la acción de los cambios térmicos y de los fluidos orales sobre el margen/restauración, hace que sea frecuente la aparición de microfiltración y tinciones en la interfase cementante, lo que dará lugar a un problema estético tanto más importante cuanto más visible sea el margen (caso de las ubicaciones supra y yuxtagingivales) a pesar de una mejor accesibilidad para la higiene.

El tipo de margen más adecuado es el de chaflán curvo largo y aunque ya se va conformando cuando hacemos las reducciones vestibular, proximales, etc., el perfilado final se logra pasando sucesivamente por el nivel deseado el extremo redondeado de la fresa tronco-cónica utilizada para la reducción vestibular; no hay que decir que el margen gingival se continúa imperceptiblemente con el de la reducción proximal.

\subsection{Maniobras finales}

Una vez completado el tallado, las maniobras finales consisten en el 


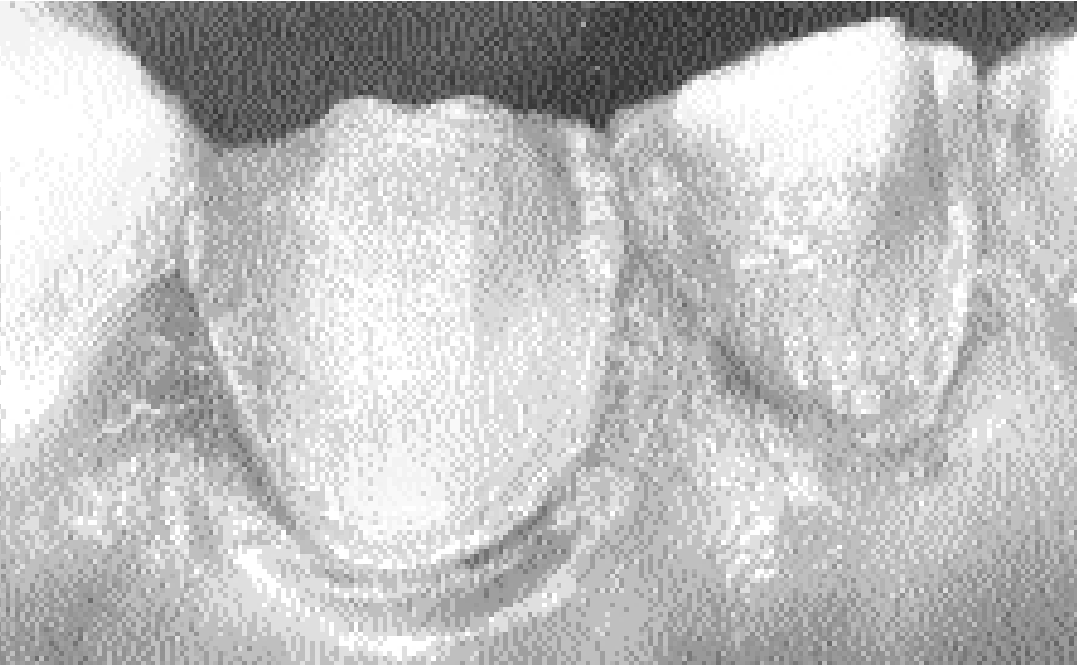

Figura 12. Preparación supragingival.

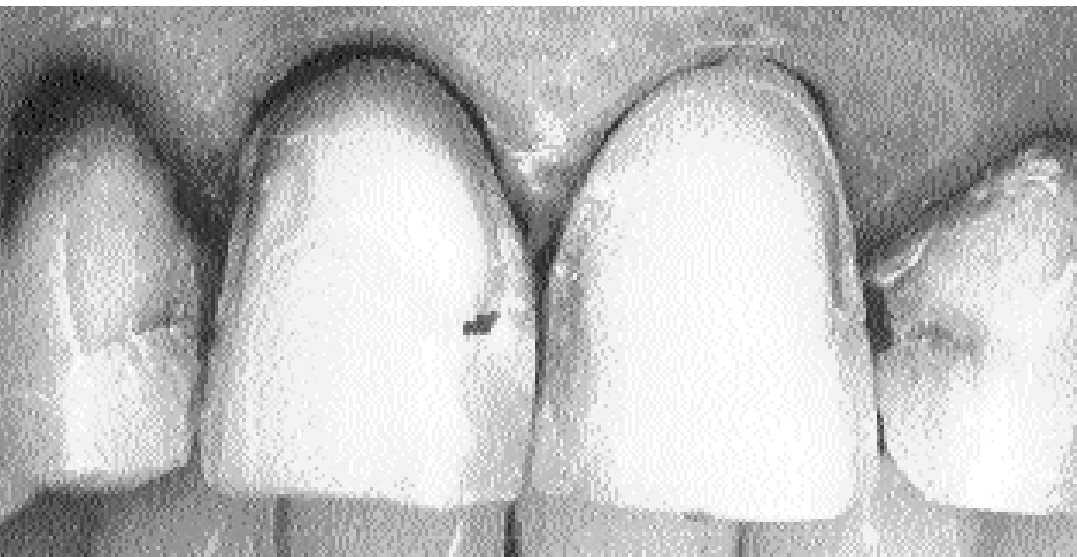

Figura 13. Empleo de hilos retractores para conseguir márgenes subgingivales, en un caso con alteraciones de coloración dentaria secundarias a tratamiento endodóntico.

redondeamiento de todos los ángulos y aristas con una fresa diamantada de bala o redonda, junto con el alisado de la preparación con diamantados de grano fino y superfino. Este alisamiento superficial permite una mayor adaptación de la carilla a la superficie dentaria, lo que minimizará la probabilidad de fractura por sobreesfuerzo tensional. Por otra parte, se facilitará rotación. Con el paso del tiempo, los dientes sufren un lento desgaste que hace que una parte del esmalte superficial, o el borde incisal haya ido desapareciendo. Si tenemos de partida esta situación de desgaste como referencia para la profundidad del tallado, significa que se perderán algunas décimas del esmalte que podrían ser conservadas.

Para obviarlo se coloca la llave de silicona construida a partir del encerado de estudio sobre el diente ${ }^{12^{*}}$, lo que permite apreciar cuanta estructura dentaria falta para lograr la forma y el volumen dentario ideal. La estructura dentaria perdida por desgaste ha de ser considerada como ya tallada, con lo que las referencias de profundidad no deben tomarse desde la superficie dentaria actual sino desde la superficie interna de la llave hasta la superficie del diente. Sólo será necesario tallar la cantidad de estructura suficiente para que la llave de silicona indique de 0,5 a 0,7 $\mathrm{mm}$ de espacio. Como la llave presenta varias rodajas horizontales, desde incisal a gingival, permite hacer la comprobación a lo largo de toda la altura dentaria de modo que la preparación vestibular será llevada a cabo mediante diamantados cónicos de punta redondeada, de tres calibres diferentes. Se empleará entonces la fresa cuyo calibre se ajuste a la reducción necesaria, efectuando surcos de profundidad verticales, desde distal a mesial de cada diente. Cada una de las ranuras se irá comprobando individualmente con la llave, y a lo largo de toda su longitud inciso gingival con las diferentes rodajas, hasta conseguir una preparación uniforme de pro- 


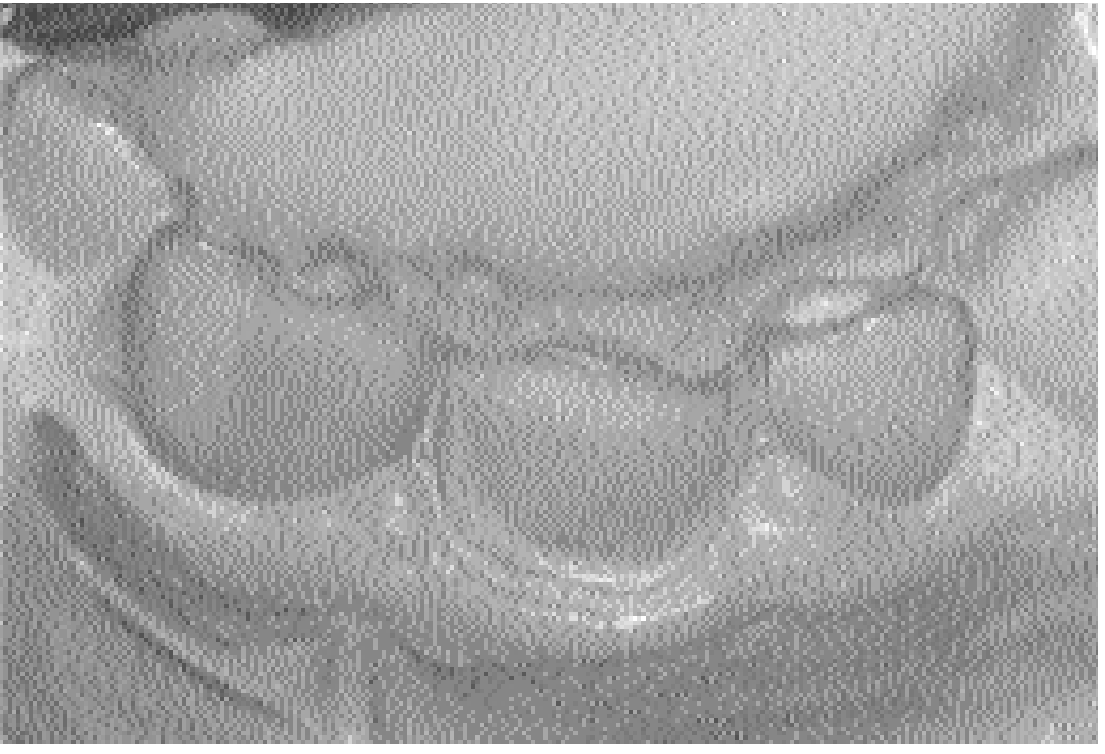

Figura 14. Impresión tomada tras la retirada del hilo retractor:

fundidad adecuada, respetuosa al máximo con la estructura adamantina remanente.

\section{Elección del color}

Una vez realizado el tallado, o incluso antes de iniciado, se procede a la elección del color. Para un mejor resultado conviene elaborar un esquema, un mapa de color necesario para la comunicación con el laboratorio. Este mapa reflejará todas las discromías superficiales del diente tallado. Consistirá en un dibujo del diente a tratar con todas las pigmentaciones y marcas que podamos detectar en él ${ }^{17}$. La reducción dentaria pondrá de manifiesto con mayor viveza todavía las alteraciones del color existentes en la dentina, que habrá que marcar en el mapa de colores destinado al laboratorio. Se adjuntarán las instrucciones precisas de color para las carillas, junto con una macrofotografía de los dientes tallados, de los dientes sin tallar y de la cara del paciente, tanto de frente como de perfil.

\section{Impresiones y modelos}

Cualquier técnica de impresión convencional para prótesis fija es adecuada para la obtención de modelos óptimos para la realización de carillas cerámicas. Todas las técnicas de impresión preseninconvenientes que para la toma de impresiones de prótesis fija, por lo que remitimos al lector a cualquiera de los tratados de prótesis fija que abundan en la cuestión. No obstante tenemos que decir que las impresiones para carillas se pueden realizar con cubetas parciales aunque son más adecuadas las cubetas de arcada completa. De ellas se obtendrán modelos completos que pueden tan las mismas dificultades, ventajas e ser montados en un articulador semiajustable con los registros correspondientes. Esto nos dará la posibilidad de comprobar los puntos de contacto así como las trayectorias excursivas, tanto más importantes cuanto más se extienda hacia palatino la terminación incisal.

En cuanto al material de impresión los mejores resultados se obtienen con los poliéteres, de una o dos viscosidades, seguidos de las siliconas de adición con técnica de doble mezcla y doble impresión (masilla y fluida) o con una sola mezcla y una sola impresión (fluida de viscosidad media o regular). El vaciado debe realizarse en yeso tipo IV de la clasificación de la ADA, como mínimo.

Retracción gingival. Se hace necesario el empleo de medios o técnicas de retracción gingival en aquellos casos en que se quiera situar el margen gingival por debajo de la encía colocando, como siempre, un hilo muy delgado en el fondo del surco y uno más grueso por encima. En el momento de tomar la impresión, se retira el hilo grueso permitiendo la penetración del material de impresión en el surco, lo que permite reproducir fielmente la situación del margen tallado (fig. 14).

En casos de márgenes supra o yuxtagingivales no es necesario el uso de hilos retractores aunque se pueden emplear métodos de retracción químicos como p. ej.: el caolín que permite una retracción gingival suficiente, así como el desecado del surco crevicular y del margen de la preparación. También se pueden combinar ambos métodos, colocando un único hilo en el fondo del surco, ayudado del efecto hemostático y retractor del caolín en el margen. 
Se lleve a cabo o no la citada retracción gingival, se hace necesario proteger el complejo dentinopulpar antes de proceder a la toma de impresiones mediante el tratamiento superficial del diente con un adhesivo dentinario. Se producirá la obliteración de los conductillos que hayan podido quedar expuestos, impidiendo la posible afectación pulpar y mejorando la futura adhesión final de las carillas definitivas.

\section{Restauraciones provisionales}

En la planificación del tratamiento hay que tomar la decisión sobre la conveniencia de colocar o no provisionales. Su confección y colocación puede ser complicada y engorrosa. Algunos autores ${ }^{18^{*}, 19}$ han sistematizado diversas técnicas para su construcción, tratando de facilitar la tarea clínica. En aquellos pacientes en los que el tallado haya sido escaso o nulo y no presenten dentina expuesta, no será necesario el uso de provisionales ya que no van a presentar compromiso estético ni sensibilidad postoperatoria. Por el contrario, aquellos pacientes que han requerido un tallado más profundo pueden presentar sensibilidad al frío y problemas estéticos. Si además se ha realizado ruptura de los puntos de contacto, existe la posibilidad de cambios de posición dentaria. Estos cambios posicionales pueden dificultar la inserción final de las carillas definitivas, al contactar estas entre sí en la boca de modo diferente a como lo hacen en los modelos de trabajo. Para evitar que se produzcan estos inconvenientes es necesario el empleo de provisionales, confeccionados de tal manera que reproduzcan los dientes del paciente antes del tallado.

Se describen dos técnicas para su construcción.

Técnica indirecta. Se obtiene un modelo maestro a partir de unas impresiones preliminares de los dientes sin tratar y se enceran ligeramente, para corregir alteraciones menores y así facilitar la construcción de los provisionales. Se construye una llave de silicona del modelo y a continuación se tallan ligeramente los dientes que van a recibir las carillas, menos que lo que se hará en la boca. A continuación se carga la llave de silicona con acrílico autopolimerizable y se coloca sobre el modelo previamente impregnado de separador de acrílico; llave y modelo se solidarizan y se introducen en una olla a presión de 1,5 a 2 atmósferas, durante 10 minutos. Así se obtiene una restauración provisional que feruliza en bloque todas las carillas a construir para el paciente. La ferulización permite una mayor resistencia del provisional, que es muy endeble. Además limita la posible movilidad de los dientes tallados. El provisional así obtenido, tras su ajuste y repasado, no se ajusta exactamente al diente después del tallado, lo que obligará a un rebase de los provisionales en la boca del paciente. Sólo así se consigue un ajuste impecable del provisional a los márgenes tallados. La cantidad de acrílico autopolimerizable a emplear en el rebase intraoral es tan pequeña que el diente puede absorber la elevación de temperatura subsecuente a la reacción exotérmica sin sufrir alteración. Por otra parte, la can- tidad de monómero que pueda quedar libre sobre el diente no va a ser capaz de afectarle. Si además, previamente a esto se ha tratado la superficie dentaria con adhesivos dentinarios de protección, la seguridad es casi completa y más si al inicio de la reacción exotérmica del acrílico se retira el provisional de la boca y se espera la polimerización final fuera de la misma.

Otra manera más precisa de confeccionar provisionales por la técnica indirecta consiste en tomar una impresión de alginato de los dientes tallados, tras las impresiones definitivas. Se vacía este registro con escayola de fraguado rápido, (3 partes de escayola snow white no 2 de Kerr y 1 parte de escayola tipo IV de la ADA) lo que permite obtener un modelo de trabajo que reproduce los dientes ya tallados. También se puede hacer un segundo vaciado de la impresión definitiva, si el material de impresiones lo permite. Sobre este modelo se construyen los provisionales como se describió anteriormente, cuyo ajuste va a ser suficiente, no siendo necesario rebasarlos intraoralmente, sino que se podrán cementar directamente tras los ajustes mínimos de eliminación de rebabas o de añadido de muy pequeñas cantidades de acrílico autopolimerizable en los márgenes. Incluso este añadido puede realizarse con dosis mínimas de composite fluido inyectado en el posible margen abierto, tras el cementado. El inconveniente de esta técnica es que se precisa de un tiempo extra, mientras se vacía la impresión y se fragua la escayola de fraguado rápido.

Técnica directa. Se confeccionan directamente en la boca del paciente, mediante una llave de silicona cons- 
truida sobre el encerado de estudio, 0 mediante una impresión de alginato que se toma de los dientes del paciente en el momento previo al tallado ${ }^{20}$. Tras la reducción dentaria, se protegen los dientes con un adhesivo dentinario. La superficie tallada está mayormente cubierta por esmalte, con lo que la protección del adhesivo es muy eficaz. Ahora se carga la llave de silicona o la impresión de alginato con acrílico auto o termopolimerizable, después de haber aplicado un separador acrílico a la superficie dentaria tallada. Se evita así la unión de la resina al adhesivo dentinario y al diente y no hay dificultad para retirar los provisionales de la boca para su posterior ajuste. Una vez comenzada la reacción exotérmica se retiran de la boca la llave o la impresión de alginato y se espera la polimerización completa a temperatura ambiente o en la olla a presión, como ya se citó.

Acabado y pulido provisional. Obtenidos los provisionales se procede a su repasado con fresas de laboratorio para eliminar los excesos y las rebabas. Se finalizan mediante discos de pulir de papel, tipo Sof-lex con los que se pulirán todas las superficies, con especial atención a los márgenes, que finalizarán perfectamente ajustados y pulidos. De este modo se reduce la porosidad del provisional y el riesgo de una gingivitis que pueda dificultar el posterior cementado de las carillas. El resto de las superficies también se pueden pulir con copas de pulido de composites. Pueden pulirse a alto brillo con una pulidora de laboratorio, o bien se pueden pincelar con Duralay y polimerizarlos.

Tras el pulido de los provisionales se procede a su cementación con cemento provisional. Este cementado sobre preparaciones dentarias poco o nada retentivas -caso de los dientes tallados para carillas cerámicas-, trae como resultado una gran facilidad para descementarse prematuramente, antes de las fechas previstas para la instalación de las carillas definitivas. Es necesario advertir al paciente de esta posibilidad, e instruirle en como cementarlos de nuevo, temporalmente, en el caso de un desprendimiento accidental.

Un método sencillo es el empleo de un adhesivo de cianocrilato, de uso comercial, pincelando una delgada capa del mismo en la cara interior de los provisionales y colocando estos a continuación. Los adhesivos de cianocrilato son fáciles de emplear, y el propio paciente puede emplearlos a domicilio en caso de un descementado inoportuno. Hay que indicarles el uso de una pequeña cantidad de cianocrilato, para que queden bien colocados, sin desplazamientos por el grosor de la película adhesiva.

Los cementos de clínica para cementados temporales deben atender a la necesidad futura de cementado adhesivo de las carillas cerámicas. Por lo tanto, es necesario no alterar la superficie dentaria mediante el empleo de cementos que interfieran con la adhesión. Hay que utilizar cementos de base de hidróxido de calcio o bien de óxido de zinc sin eugenol, todos ellos con una capacidad retentiva de los provisionales suficiente durante 2 o 3 semanas.

También es posible cementar los provisionales mediante cementado adhesivo, para lo que se realiza un grabado ácido puntiforme sobre el centro de la cara vestibular de los dientes preparados, seguido de la aplicación de un adhesivo dentinario sobre la superficie preparada. Se impregna también la cara interna de los provisionales y se adapta bien a la superficie dentaria. A continuación se fotopolimeriza desde las superficies vestibulares, con lo que se obtiene una adhesión relativamente fuerte sin que la gran mayoría de la superficie dentaria se vea comprometida.

\section{Prueba de las carillas}

Tras la fabricación por el laboratorio de las carillas cerámicas, el siguiente paso clínico es su ubicación en la boca del paciente. A diferencia de las coronas cerámicas de recubrimiento total y de otras restauraciones ceramometálicas no es frecuente hacer una «prueba de bizcocho» y realizar pruebas y correcciones posteriores. Por eso, en la mayoría de las ocasiones las carillas cerámicas vendrán acabadas del laboratorio y habrá que hacer ajustes intraorales menores para que su asentamiento sobre los dientes sea lo más exacto posible.

No obstante, se comprobará cada una de las carillas en sus aspectos de estética, ajuste y orden de cementado. a. Estética. Se evaluará el color que las carillas presenten, así como su translucidez y capacidad para enmascarar alteraciones del color subyacentes. El color de la carilla no podrá cambiarse, pero sí es posible modularlo mediante el empleo de cementos con color. Los diferentes sistemas de cementado adhesivo están dotados de cementos con coloraciones diferentes que permiten modificar el color de las carillas, dada su translucidez. Además, estos sistemas de cementa- 
do presentan pastas de prueba que reproducen el cambio de coloración que el cemento inducirá, pero no tienen capacidad de fraguado. De este modo, el operador puede proceder a la prueba de diferentes combinaciones de colores en la búsqueda del resultado estético final. También se pueden usar intensificadores de color o tinciones, como naranjas para el cuello dentario y azules para los bordes incisales o los marginales. Se consiguen así realces de la naturalidad de las carillas. Por último se pueden emplear opaquers que enmascararán cualquier defecto de coloración que el diente presente en su superficie. Estos opacificadores han de ser usados con precaución pues su efecto se basa en la total reflexión de la luz sobre ellos, sin permitir que ésta les atraviese para reflejarse en las capas más profundas. Como consecuencia se pierde algo de naturalidad en la carilla, que se vuelve más densa y compacta al ojo del observador.

b. Ajustes. La forma y el tamaño de las carillas debe reproducir el encerado diagnóstico, si se ha hecho, y se ha de comprobar como ajustan los márgenes de la carilla al diente. Hay que eliminar cualquier sobrante de cerámica que impida la correcta inserción de la carilla, además de revisar cualquier ángulo de la restauración que pueda estar ocupado por rebabas cerámicas que hayan pasado desapercibidas. Para ello se coloca la carilla y con presión digital ligera se comprueba su asentamiento, sin presencia de puntos de fulcro por apoyos puntuales.

c. Orden de cementado. Por último se comprobará el orden de cementado, pues no siempre ajustan todas las carillas en el orden que al operador le

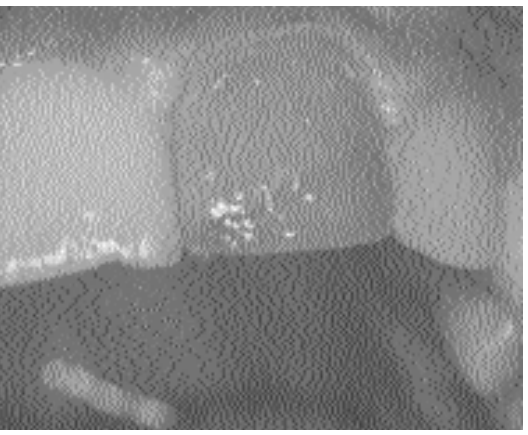

Figura 15A. Grabado del esmalte del diente tallado.

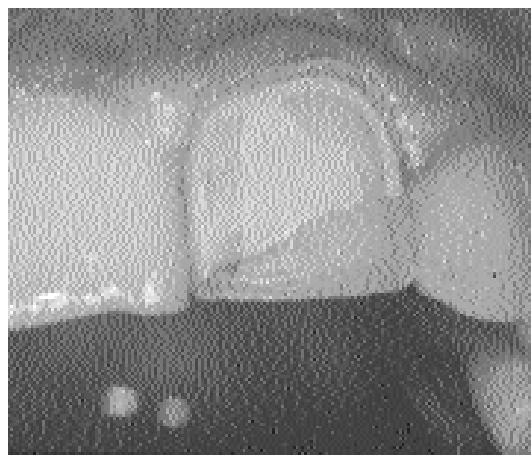

Figura 15.B. Superficie dentaria tras el grabado del esmalte.

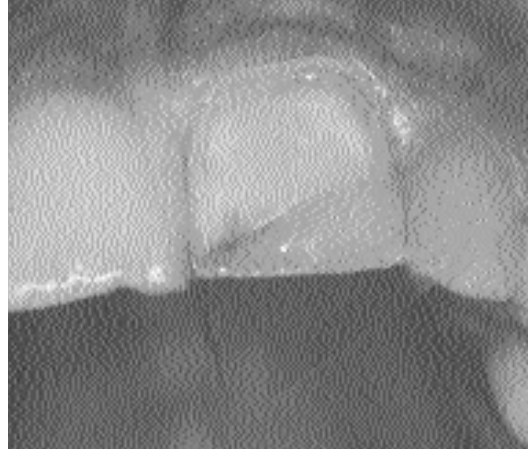

Figura 16. Aplicación de bonding a toda la superficie dentaria tallada.

parece lógico. En ocasiones, el contacto de una carilla con su vecina introduce desplazamientos imperceptibles en la posición de ambas. A medida que se van colocando nuevas carillas, la discrepancia va siendo mayor, de manera que puede ocurrir que las últimas carillas presenten un grado de dificultad elevado para su correcto asentamiento sobre el diente. Por eso se necesita comprobar el orden de cementado y anotarlo, para reproducirlo de nuevo a la hora de proceder al mismo.

\section{Cementado de las carillas}

Tras solucionar los posibles problemas planteados en la prueba se procede a la cementación de las carillas, proceso que incluye los siguientes apartados: acondicionamiento del esmalte, preparación del diente, preparación de la carilla, cementado propiamente dicho, maniobras finales, acabado y pulido.

\section{Acondicionamieneto del esmalte.}

El esmalte de las superficies dentarias se prepara para la adhesión según las indicaciones del cemento adhesivo que se vaya a emplear. Primeramente será necesario limpiar las superficies sobre las que se asentará la carilla. Tras las pruebas estéticas realizadas es imprescindible eliminar cualquier residuo de cemento remanente.

Se prepara la encía para que el margen de la preparación quede perfectamente accesible para el asentamiento de la carilla, sin interferencias del tejido blando y de modo que el fluido crevicular no contamine las superficies a adherir. Para ello será necesario volver a colocar hilo de retracción, sobre todo con márgenes subgingivales. Generalmente no se puede utilizar diques de goma para aislar los dientes a tratar con carillas cerámicas.

Después se graba el esmalte talla- 
do, con ortofosfórico al 7\%9,6\% durante 15 segundos, seguido de lavado con abundante agua (figs. 15a y b). La contaminación salival del esmalte grabado implica un nuevo grabado del esmalte, durante 10 seg. El esmalte grabado es, a continuación, pincelado con el agente adhesivo, o bonding, siguiendo escrupulosamente las indicaciones del fabricante, pincelando una o varias capas de adhesivo hasta conseguir la cobertura total de las superficies a tratar. Se evapora el agente solvente con un suave chorro de aire de la jeringa del equipo, durante 4 o $5 \mathrm{seg}$. Se polimeriza el adhesivo cuando así se recomiende por el fabricante, y las superficies dentarias deben presentar ahora un aspecto brillante y húmedo (fig. 16).

\section{Acondicionamiento de la carilla.}

Tras las pruebas de color es necesario lavar las carillas perfectamente, eliminando cualquier residuo de composite de prueba que pueda quedar en su interior. Para ello pueden introducirse en el baño de ultrasonidos, si es que no puede eliminarse del todo la pasta de prueba. Después se acondiciona la carilla con ácido fluorhídrico durante 1 a 4 minutos (fig. 17), para las cerámicas que puedan grabarse. A continuación se lavan con chorro de aire-agua y se secan totalmente las carillas grabadas, lo que va seguido de la silanización de la carilla pincelando el interior de la misma con el líquido silano, que se deja actuar durante un minuto. Hay que mantenerlas completamente humectadas por el silano, para que la reacción química de éste con la cerámica sea completa. Ahora se seca el silano totalmente, con aire caliente o con el chorro de aire de la jeringa (fig. 18).

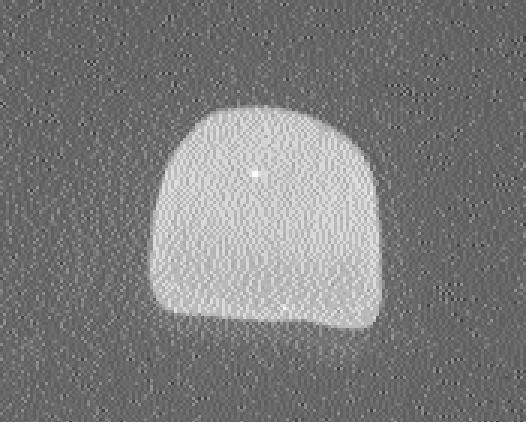

Figura 17. Acondicionado de la carilla con ácido fluorhidrico.

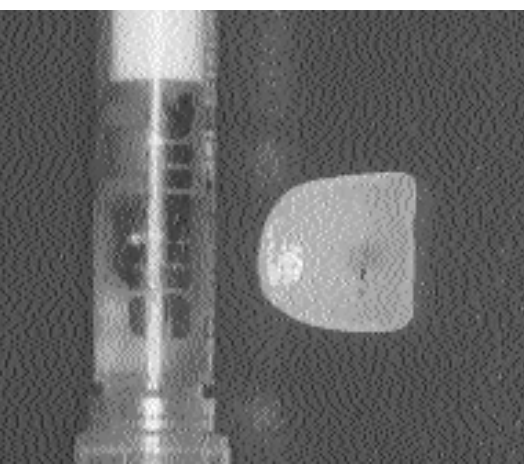

Figura 18. Carilla silanizada.

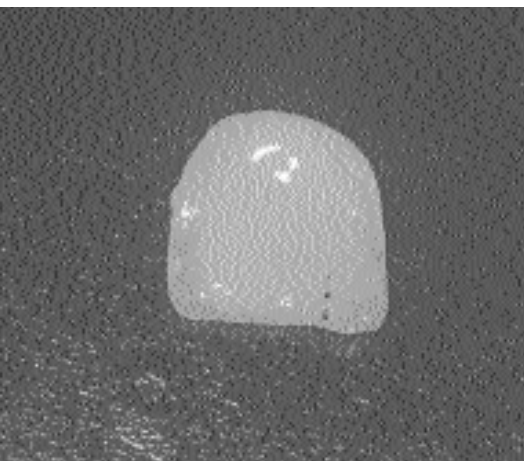

Figura. 19. Carilla cargada con el cemento composite.

Con algunos tipos de cerámica no es necesario el grabado de la carilla, por ser la cerámica resistente al ataque ácido. En este caso se procede a chorrearla en su cara interna y márgenes, con partículas de óxido de alumi- nio de $80 \mu$ a alta presión. El resultado es una superficie interna con retención micromecánica similar a la de la cerámica grabada, y semejantes propiedades retentivas. A partir de aquí se seguirán las instrucciones del fabricante del cemento adhesivo en lo que se refiere a la aplicación del bonding a la cara interna de la carilla silanizada.

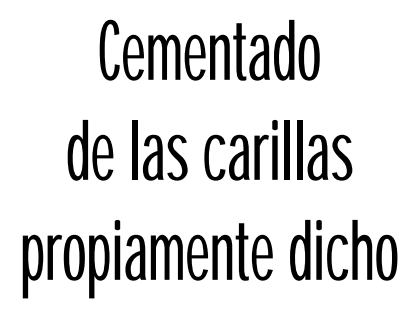

Una vez efectuado el acondicionamiento del esmalte y carilla y seleccionado el cemento a utilizar, tras su mezcla adecuada en cantidad suficiente, se posiciona una fina capa del composite sobre el diente, con ayuda de una espátula, procurando que lo cubra uniformemente y no queden zonas sin relleno. El cemento será un composite suficientemente fluido, fotopolimerizable o de polimerización dual (fig. 19). Al mismo tiempo se coloca en la cara interna de la carilla el cemento con las diferentes combinaciones de color decididas en las pruebas. Durante todo este proceso hay que proteger el composite de la luz del equipo y ambiental, para evitar un prepolimerizado que impida el asentamiento correcto de las carillas.

Para el transporte de la carilla desde la mesa de trabajo hasta la boca existen diversos aditamentos que sirven para sostenerla con cierta fuerza. Sin embargo, los dedos enguantados son suficientes, y de gran precisión como para que no sea necesario aumentar el armamentario de trabajo. 


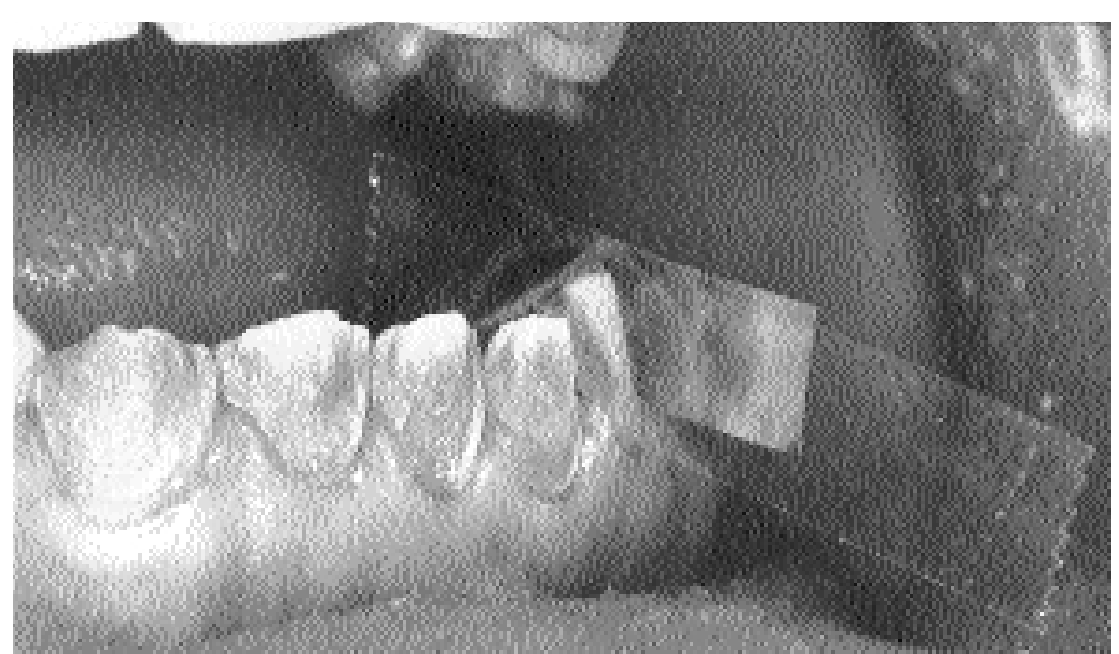

Figura 20. Tira Mylar colocada entre dos dientes.

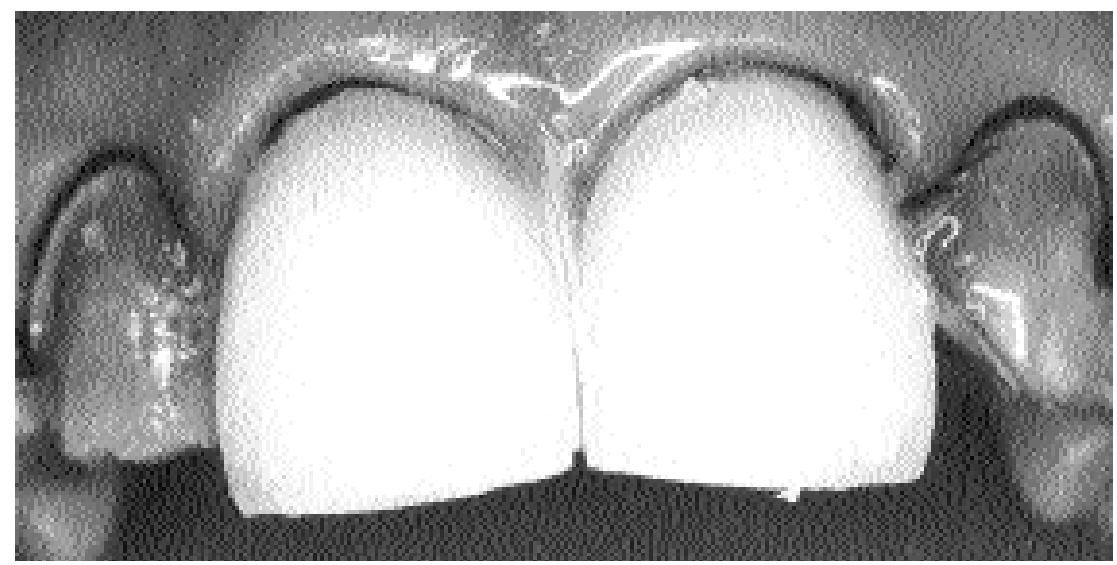

Figura 21. Cementado de carillas por pares homónimos. Se aprecia el sobrante de cemento tras retirar la tira separadora.

El uso de un cemento compuesto de baja viscosidad o fluido se justifica por la necesidad de conseguir una capa lo más fina posible de interfase. Cuanto más gruesa sea, mayores probabilidades de fracaso, pues esta interfase cementante es la parte más débil de la restauración. Para facilitar el adelgazamiento de la capa suele ser suficiente llevar a cabo un golpeteo suave de la superficie de la carilla con el mango del espejo para asentarla totalmente. En ocasiones puede utilizarse el aparato de detartraje ultrasónico, apoyando un inserto plano sobre un trozo de dique de goma situado encima de la carilla. La vibración ultrasónica puede facilitar la expulsión de los excesos de composite.

Las tinciones y opacificaciones también deben ser incluidas en la cara interna de la carilla, como se decidió en la prueba. Hay que considerar la posibilidad de desplazamiento de aquellas durante el asentamiento de la carilla, por lo que hay que ubicarlas muy exactamente para que puedan tolerar un cierto grado de corrimiento sin provocar alteración estética.

Es conveniente que el operador novel siga el orden de cementado decidido durante la prueba, y cementar una a una las carillas. Cuando el profesional haya adquirido experiencia no necesita llevar a cabo el cementado individual y pueden cementarse todas a la vez, en una sola pasada. No debe olvidarse la conveniencia de colocar tiras de acetato de celulosa o similar entre los dientes, antes de la polimerización del cemento de composite, para evitar la unión del cemento sobrante (fig. 20). Hornbrook ${ }^{20}$ propone una técnica de cementado específica, denominada por el autor «técnica dos a dos», en la que cementa las carillas por pares homónimos. De esta manera, dice el autor, se reduce la sensibilidad a la técnica de cementado y el tiempo de clínica (fig. 21).

Una vez conseguido el asiento correcto de la carilla se lleva a cabo un polimerizado puntiforme con la lámpara halógena equipada de un inserto de $2 \mathrm{~mm}$ de diámetro. Poniendo éste en el centro de la cara vestibular de la carilla, se mantiene la luz durante 3-5 segundos y se apaga. Con esta maniobra se consigue fijar la carilla en su posición definitiva al polimerizarse el cemento que está situado justo por debajo del punto de aplicación de la luz. Sin embargo, los sobrantes que han fluido por los márgenes están todavía en fase plástica, lo que permite al operador eliminarlos mediante el uso del instrumental apropiado, como sondas exploradoras, hojas de bisturí, seda 
dental en los espacios interproximales, etc. Se trata de eliminar el máximo posible de excedente del cemento antes de que esté polimerizado totalmente, pero siendo muy cuidadosos para no dejar ningún margen expuesto o sin relleno. Una vez eliminados todos los excesos se procede a completar la polimerización del cemento composite de adhesión. Para ello se emplean fibras ópticas de gran diámetro, que abarquen la mayor superficie posible. Se aplica la luz durante 20 a 40 segundos desde todos los ángulos posibles, a todos los márgenes, tanto desde vestibular como lingual, para asegurar el sellado de la interfase lo más posible. Se pueden emplear dos lámparas a la vez, una desde vestibular y otra desde lingual, acortando así el tiempo de trabajo necesario para la total polimerización. El tiempo de iluminación depende del tipo de lámpara.

Un caso particular a considerar son las recesiones gingivales. Cuando hay que cerrar espacios interradiculares, por presencia de recesiones gingivales con exposición radicular, se pueden emplear cerámicas especiales coloreadas en rosa, para fabricar carillas que permitan recrear la papila ${ }^{21}$. En estos casos, el cementado se realiza con cementos de vidrio ionómero reforzados con resina, pues a nivel del cemento radicular, la unión al cemento composite es peor, con mayores posibilidades de filtración marginal y descementado. Sin embargo, la unión de éste a la carilla es superior a la conseguida con el vidrio ionómero híbrido. La carilla servirá en estos casos para la mejora de la fonética ${ }^{22}$ del paciente, al cerrar el hueco por el que el aire se escapa durante la dicción.

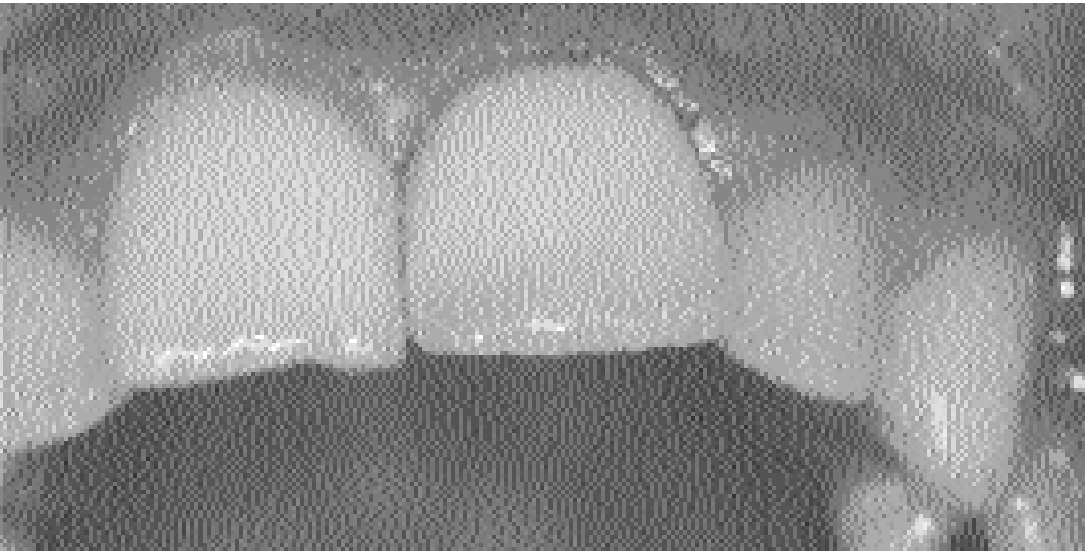

Figura 22. Caso terminado con carilla individual.

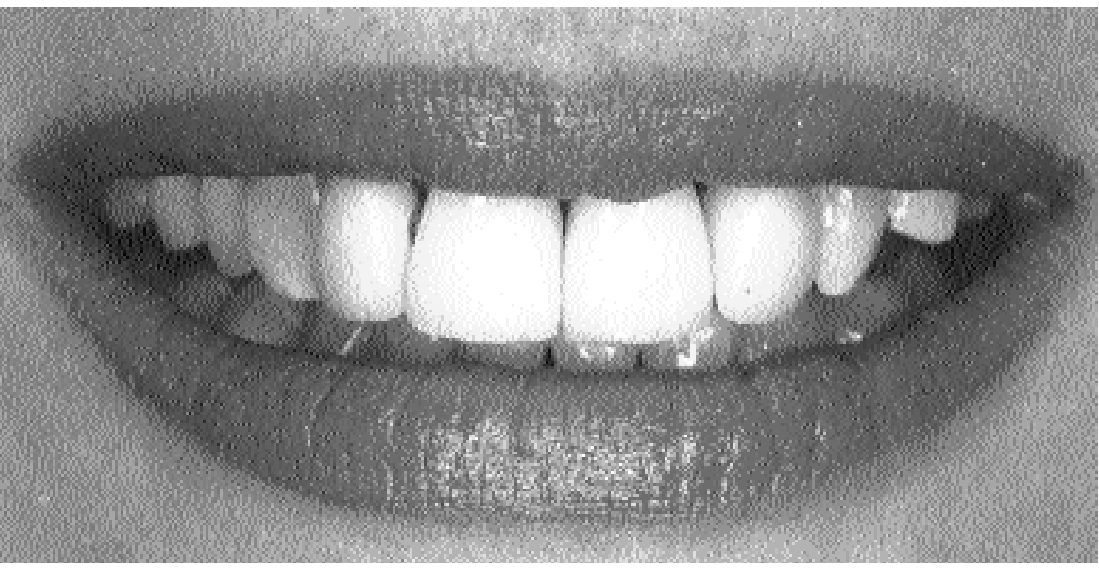

Figura 23. Caso terminado, restauración de frente anterior completo.

\section{Maniobras finales.}

\section{Acabado, pulido y control postoperatorio}

Finalizada la polimerización y cementada la carilla se procede a eliminar todos los restos remanentes de cemento, teniendo especial cuidado en las áreas no visibles, o sea, en los espacios interproximales y en las zonas subgingivales. Tras repasar con el explorador todo el surco crevicular, se pasa la seda dental entre cada una de las carillas. Allí donde se detecten restos de cemento se eliminarán, para lo que se puede utilizar sierras interproximales, tiras de pulido de diferentes granulometrías, etc. Si es necesario recurrir al instrumental rotatorio para eliminar cualquier residuo excesivamente adherido, se utilizarán las fresas multifilos de carburo de tungsteno o los diamantados de grano ultrafino que se emplean en el pulido de los composites. Si además fuese necesario contornear la porcelana, las restantes fresas diamantadas de granulome- 
tría ultrafina y de perfil recto son las adecuadas para esta misión, pero hay que recordar que la porcelana glaseada es la superficie más lisa de todas las que se pueden lograr. Es preferible no tener que tocarla con fresas, pues aunque procedamos a su pulido a alto brillo, con los medios de pulido de cerámica existentes en el mercado, no se podrá lograr una superficie tan lisa como la que se consigue en el laboratorio dental con el glaseado.

En la última fase del acabado se procede al ajuste de oclusión, exactamente igual que para los ajustes de prótesis fija. Habrá de eliminarse cualquier prematuridad o interferencia, así como situaciones de supraoclusión que afecten a un diente y puedan suponer una sobrecarga con posterior fractura. Los contactos deberán ser repartidos y uniformes, y siempre que sea posible se deben aprovechar las carillas para proveer de oclusión orgánica al paciente. Tras el ajuste oclusal hay que pulir todas las superficies afectadas por los diamantados. Se completa el caso con la revisión general y la documentación fotográfica del mismo (fig. 22 y 23). Los casos terminados se documentarán fotográficamente

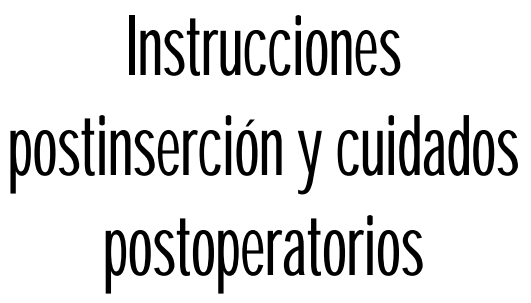

En las primeras horas tras el cementado se debe indicar al paciente la necesidad de ser cuidadoso con la función masticatoria, pues el cemento aún continúa su polimerización, de modo autopolimerizable, durante un cierto tiempo tras la fotopolimerización. Las tensiones de fraguado van disipándose lentamente hasta un tiempo variable después de la cementación. Un plazo de seguridad son de 48-72 horas, en las que el paciente ha de evitar la masticación intensa, así como las comidas con temperaturas extremas de frío y calor. Sobre todo hay que evitar las transiciones bruscas de un extremo térmico a otro, pues los cambios dimensionales por esta causa afectan de manera diferente al esmalte, al composite y a la cerámica, lo que generará tensión en la interfase. Ya se había citado que ésta era la parte más débil de la restauración y en esta fase inicial del tratamiento no se ha terminado de consolidar todavía.

Por otro lado el paciente no debe llevar a cabo ninguna clase de hábito inadecuado, tales como el mordisqueo de bolígrafos, clavos, uñas o cualquier otra cosa y especialmente la masticación de hielo, que causa una gran disminución de temperatura a nivel dentario con la consiguiente contracción térmica. En los casos en que el paciente presente un hábito de apretamiento o rechinamiento dentario u otras parafunciones con sobrecarga, es de uso obligado una férula oclusal o desprogramador neuromuscular al menos en los periodos de sueño. Además es preciso convertirle en oclusoconsciente, para que durante los periodos de vigilia no apriete los dientes.

Es necesario que el paciente reciba instrucciones precisas y motivación para que consiga un buen control de placa e higiene oral.

Tras la información sobre las precauciones y cuidados a tener en cuen- ta, el paciente debe ser controlado periódicamente en la consulta, al menos dos veces al año, en las que se deben llevar a cabo ajustes de la férula de descarga, control estético, control funcional y procedimientos de higiene oral profesional en las que no se debe afectar a la cerámica con ultrasonidos o pastas abrasivas, ni con el raspado, ya sea ultrasónico o manual. Los higienistas dentales deben estar instruidos adecuadamente en este sentido.

\section{Complicaciones y fracasos}

Como para cualquier tipo de restauración protésica el tratamiento con carillas no está exento de complicaciones y fracasos aunque se reducen al mínimo cuando la indicación es correcta y la técnica lo más depurada posible.

Entre las complicaciones más inmediatas está la hiperestesia dentaria, tanto más intensa cuanto más profundo haya sido el tallado y menos protección haya recibido el diente. Entre los fracasos a medio y largo plazo tenemos el descementado, la fractura y el fracaso estético.

a. Descementado: se puede producir descementado de las carillas de cerámica, con desprendimiento en bloque de una o varias, en cualquier momento tras el cementado, desde poco tiempo tras el mismo hasta varios años después. La solución consiste en el recementado de la carilla después de la limpieza exhaustiva de las superficies de adhesión. Es necesario investigar los motivos del despren- 
dimiento de la carilla, viendo donde se ha producido el fallo de cementado, bien en la unión cemento/porcelana, bien en la unión cemento/diente $o$ en el espesor de la interfase cementante para solucionar el problema con un criterio causal.

b. Fractura: ocasionalmente se produce la fractura de un fragmento de la carilla cerámica. Es el fracaso más frecuente. La solución inmediata consiste en el recementado del fragmento, pero esta solución no es la más aconsejable en el tiempo, pues habitualmente se produce una infiltración en la línea de fractura, con tinción estéticamente inaceptable. L más aconsejable es la sustitución total de la carilla a la vez a que se indaga en la posible causa de la fractura (bruxismo, hábitos inadecuados, golpe, sobrecarga por contactos inadecuados, grosor cerámico incorrecto, etc.) con el fin de eliminarla y que no se convierta en un fracaso recidivante.

c. Fracaso estético: se produce cuando existe un error en alguno de los elementos constitutivos de la estética de la carilla, es decir, el color, la forma o la integración de la carilla en la sonrisa del paciente. Es necesario repetir el tratamiento completo.

La situación más complicada se produce cuando existe una expectativa no realista por parte del paciente. Si el profesional no es capaz de trasmitir al paciente las limitaciones de la técnica se producirá un fracaso estético seguro, porque el paciente no alcanzará los resultados que espera. Por otra parte, algunas personas tienen un criterio estético individual que puede diferir mucho de la normalidad, considerando inadecuados resultados que para nosotros serían suficientes. En este caso es necesario detectar con antelación la personalidad de estos pacientes, que nunca van a estar satisfechos con el resultado final.

Otro tipo de fracaso estético es la tinción de la interfase cementante, por filtración o tinción excesiva. Si el hecho se produce en áreas visibles, la solución es la sustitución por otra con los márgenes ubicados en áreas no visibles. El problema es similar cuando se produce tras una recesión gingival que deja al descubierto los márgenes.

\section{Conclusiones}

La cerámica dental sin metal, y con ella las carillas, ha entrado de lleno en el componente estético de la restauración protésica, en especial en lo que se refiere al sector anterior, el de la sonrisa. Las carillas cerámicas han probado su eficacia, predecibilidad y escasez de fracasos a largo plazo, siempre con indicaciones y técnica precisa. Esto, unido al conservadurismo de la técnica, que permite llevar a cabo tratamientos con escasa eliminación de sustancia dentaria, pone en manos del odontoestomatólogo una herramienta de tratamiento que va a aportar satisfacción, tanto al profesional dental como a sus pacientes.

\section{Bibliografía recomendada}

Para profundizar en la lectura de este tema, el/los autor/es considera/an interesantes los artículos que aparecen señalados del siguiente modo: *de interés ${ }^{* *}$ de especial interés.

1. Morig G. Aesthetic all-ceramic restoration: a philosophyc and clinical review. Pract Proced Aesthet Dent 2003; Suppl:19-26.

2. Chu SJ, Ahmad I. Light dynamic properties of a sinthetic low-fusing quartz glass ceramic material. Pract Proced Aesthet Dent 2003;15: 49-56.

3. Peumans M, Van Meerbeek B, Lambrechts P, Van Ehrle G. Porcelain veneers: a review of the literature. J Dent 2000;28:163-7.

4. Cho GC, Donovan TE, Chee WW. Clinical experiences with bonded porcelain laminate veneers. J Calif Dent Assoc 1998;26:121-7.

5. Walls AW, Steele JG, Wassell RW. Crowns and other extra-coronal restorations: porcelain laminate veneers. Br Dent J 2002;193:79-82.

6*. Aristidis GA, Dimitra B. Five-year clinical per- formance of porcelain laminated veneers. Quintessence Int 2002;33:185-9.

Estudio prospectivo a 5 años del comportamiento clínico de las carillas de porcelana.

7**. Ascheim KW, Dale B. Odontología estética. Segunda ed. Madrid: Ed. Harcourt, 2002.

Los autores muestran ayudas clínicas de gran interés para el profesional dental.

8. Crispin BJ. Indirect composite restoration: alternative or replacement for ceramic? Compend Contin Educ Dent 2002; 23: 611-4.

$9 * *$. Touati B, Miara P, Nathanson D. Carillas de porcelana. En: Odontología estética y restauraciones cerámicas. Cap 9, pp 161-213. Barcelona: Ed. Masson, 1998.

Revisión profunda de la cuestión con esquemas e ilustraciones muy clarificadoras.
10. Edelhoff D, Sorensen JA. Tooth structure removal associated with various preparation designs for anterior teeth. J Prosthet Dent 2002;87:503-9.

$11^{* *}$. Chiche JG, Pinault A. Prótesis fija estética en dientes anteriores. Barcelona: Ed Masson, 1998.

Los autores presentan reglas y proporciones para determinar la forma y tamaño dentarios ideales para cada paciente.

12*. Magne P, Douglas WH. Optimización del diseño y evolución de la cerámica para la dentición anterior. Quint Int edición española 2000;10:615-25.

Los autores presentan una técnica para fabricar una guía para construir las carillas provisionales y de prueba. 
13**. Anitua Aldecoa E, Gascón Mayordomo F. Frentes laminados de porcelana. En: Soluciones Estéticas en dientes con decoloraciones. Cap 7, pp 83-116. Vitoria: Ed Evagraf, 1992.

Las carillas son presentadas por los autores desde un punto de vista clínico, con iconografía fotográfica tipo atlas.

14. Cueto Suárez. Carillas de porcelana. En: Tratado de Odontología. Tomo III, Bascones y cols. Madrid: Trigo Ediciones S. L., 1998.

15**. Crispin BJ, Hewlett ER, Jo YH, Hobo S, Hornbrook DS. Bases Prácticas de la Odonto- logía estética. Barcelona: Ed Masson, 1998 En este libro se presentan gráficos claros de la preparación dentaria para carillas de porcelana

16. Gurel G. Predictable, precise and repeatable tooth preparation for porcelain laminated veneers. Pract Proced Aesthet Dent 2003;15:28.

17. Dickerson WG, Culp L. Color communication, laboratory fabrication, and cementation. Pract Proced Aesthet Dent. 2003; Suppl:40-4.

18*. Sneed WD, Knights JS. Simple technique to fabricate provisional restorations for porcelain veneers. J Esthet Restor Dent 2001;13: 115-9. Sistematización de las técnicas de construcción de provisionales en pacientes tallados para veneers, con presentación de un caso clínico.

19. Kurtz KS. Constructing direct porcelain laminate veneer provisionals. J Am Dent Assoc; 20:126-32.

20. Hornbrook DS. The «two-by-two» technique for porcelain veneer cementation: minimizing time while maximizing results. Pract Proced Aesthet Dent. 2003;Suppl:28-31.

21. Helvey GA. Closing diastemas and creating artificial gingiva with polymer ceramics. Compend Contin Educ Dent 2002;23:983-6.

22. Reichel K. Aesthetic and phonetic rehabilitation in dentistry. J Comput Dent 2002;5:305-9. 